\title{
Aeroacoustic Study of a High-Fidelity Aircraft Model: Part 1- Steady Aerodynamic Measurements
}

\author{
Mehdi R. Khorrami ${ }^{1}$, Judith A. Hannon ${ }^{2}$, Dan H. Neuhart ${ }^{2}$, and Gregory A. Markowski ${ }^{3}$ \\ NASA Langley Research Center, Hampton, Virginia, 23681 \\ and \\ Thomas Van de Ven ${ }^{4}$ \\ Gulfstream Aerospace Corporation, Savannah, Georgia 31402
}

In this paper, we present steady aerodynamic measurements for an $18 \%$ scale model of a Gulfstream aircraft. The high fidelity and highly-instrumented semi-span model was developed to perform detailed aeroacoustic studies of airframe noise associated with main landing gear/flap components and gear-flap interaction noise, as well as to evaluate novel noise reduction concepts. The aeroacoustic tests, being conducted in the NASA Langley Research Center 14- by 22-Foot Subsonic Tunnel, are split into two entries. The first entry, completed November 2010, was entirely devoted to the detailed mapping of the aerodynamic characteristics of the fabricated model. Flap deflections of $39^{\circ}, \mathbf{2 0}^{\circ}$, and $0^{\circ}$ with the main landing gear on and off were tested at Mach numbers of $\mathbf{0 . 1 6}, \mathbf{0 . 2 0}$, and 0.24 . Additionally, for each flap deflection, the model was tested with the tunnel both in the closed-wall and open-wall (jet) modes. During this first entry, global forces (lift and drag) and extensive steady and unsteady surface pressure measurements were obtained. Preliminary analysis of the measured forces indicates that lift, drag, and stall characteristics compare favorably with Gulfstream's high Reynolds number flight data. The favorable comparison between wind-tunnel and flight data allows the semi-span model to be used as a test bed for developing/evaluating airframe noise reduction concepts under a relevant environment. Moreover, initial comparison of the aerodynamic measurements obtained with the tunnel in the closed- and open-wall configurations shows similar aerodynamic behavior. This permits the acoustic and off-surface flow measurements, planned for the second entry, to be conducted with the tunnel in the open-jet mode.

\section{Nomenclature}

$\begin{array}{ll}\text { AOA, alpha } & =\text { angle-of-attack } \\ \mathrm{b} & =\text { wing span } \\ \mathrm{C}_{\mathrm{D}} & =\text { drag coefficient } \\ \mathrm{C}_{\mathrm{D} 0} & =\text { minimum drag coefficient } \\ \mathrm{C}_{\mathrm{L}} & =\text { maximum lift coefficient } \\ \mathrm{C}_{\mathrm{Lmax}} & =\text { pressure coefficient } \\ \mathrm{Cp} & =\text { local chord } \\ \mathrm{C} & =\text { Gulfstream Aerospace Corporation } \\ \mathrm{GAC} & =\text { kilo Pascals } \\ \mathrm{kPa} & =\text { Mach number } \\ \mathrm{M} & =\text { wind tunnel dynamic pressure in psf } \\ \mathrm{Q} & =\text { Reynolds number } \\ \mathrm{Re} & =\text { Pounds per square foot } \\ \mathrm{psf} & =\text { coordinate along chord } \\ \mathrm{X} & \end{array}$

\footnotetext{
${ }^{1}$ Aerospace Engineer, Computational AeroSciences Branch, Associate Fellow AIAA

${ }^{2}$ Aerospace Engineer, Flow Physics and Control Branch

${ }^{3}$ Test Engineer, Jacobs Technology, ROME Group

${ }^{4}$ Senior Acoustic Engineer, Acoustics and Vibration Group, Member AIAA
} 


\section{Introduction}

Steady improvement in the design of modern high-bypass ratio turbofan engines has transformed the airframe into a major component of aircraft noise that is equal to, if not greater than, the engines during approach to landing. Acoustic measurements from flight tests ${ }^{1-6}$ and model-scale experiments ${ }^{7,8}$ have identified the undercarriage system and the high-lift devices, such as slats and flaps, as prominent airframe noise sources. The environmental noise impact of the civil transport fleet during landing and take-off operations must be reduced to meet increasingly stringent community noise regulations. The development and evaluation of viable airframe noise abatement technology requires the availability of a high-fidelity, large-scale airframe model that would permit the assessment of candidate concepts under a relevant flight environment. The present paper discusses the steady aerodynamic testing of an $18 \%$ scale semi-span model of a Gulfstream aircraft. The model was produced specifically to conduct airframe noise studies and evaluate advanced noise reduction concepts for reducing landing gear, flap, and gear-flap interaction noise.

The present work was performed as part of the NASA-Gulfstream partnership for airframe noise research. In this partnership, executed as a Space Act Agreement under NASA's Environmentally Responsible Aviation (ERA) project, a series of flight tests and model scale experiments are being performed systematically using a Gulfstream aircraft as the baseline configuration. The joint effort began with an acoustic flight test in 2006 where the prominent airframe noise sources associated with the aircraft were identified and documented. ${ }^{6}$ The major noise sources are the flap side-edges, main landing gear, and nose landing gear. Gear-flap flow interaction was also identified as a likely source of noise. Given the relative structural isolation of the nose landing gear, a decision was made to investigate that source independently from the other sources; the aeroacoustic studies of a nose landing gear have been documented in previous papers. ${ }^{9,10}$ To facilitate detailed analyses of the remaining noise sources, a relatively large-scale semi-span replica of a Gulfstream aircraft has been designed and fabricated. This high-fidelity model will be used to better understand the principles of airframe noise generation, improve and advance airframe noise prediction tools, and develop and evaluate efficient noise reduction concepts. Particularly, some of the most challenging and still unresolved issues on airframe noise generation, such as Reynolds number, geometric fidelity, and installation effects, will be addressed. To gain knowledge on these critical effects, the model-scale experiments are closely aligned with companion flight tests, where identical flow measurements (e.g, steady and unsteady surface pressure measurements on the aircraft wing, flap, and landing gear) will be taken using identical instrumentation at exactly the same locations as those on the model,.

Aeroacoustic testing of the $18 \%$ model is to occur in a series of carefully planned entries in the NASA Langley Research Center (LaRC) 14- by 22-Foot Subsonic Tunnel (14x22). The first entry, lasting twenty-three days, was completed November of 2010. The test was devoted to mapping the aerodynamic characteristics of the sub-scale model. During this entry, in addition to acquiring the global forces (lift and drag), steady and unsteady surface pressure measurements were obtained. The early part of the second $14 \times 22$ tunnel entry will be dedicated to simultaneous acoustic and surface pressure measurements, while the latter part of the entry will be devoted to acquiring offsurface flow measurements from the baseline model landing configuration.

Given the volume of aerodynamic data already collected, and the need to provide a full description of the critical aspects of the semi-span model and the associated flow field, the present paper is devoted only to the steady measurements. An account of the unsteady data is given in a companion paper by Khorrami and Neuhart. ${ }^{11}$

\section{Model Description}

The model is an $18 \%$ scale semi-span, high-fidelity replica of a Gulfstream aircraft (see Fig. 1). It was designed, fabricated, instrumented, and integrated at NASA LaRC based on a set of geometry files provided by Gulfstream. The decision to use a semi-span configuration was based solely on the desire to maximize the model scale in order to conduct the test at a reasonable Reynolds number and to maintain high geometric fidelity. During the pre-design period, Euler computations of the model at the highest flap setting indicated that the effect of the vertical and horizontal tails on lift distribution was negligible. Based on these computations and consultations with Gulfstream engineers, the horizontal and vertical tails were excluded from the model.

\section{A. Determination of Model Scale}

The model scale was determined early in the design process in order to have an estimate for wind tunnel wall interference effects. The classical wall correction code CMWALL ${ }^{12}$ was used for this analysis. The code was modified 
to use the Maskell attached-wake blockage model instead of the apparent drag model, since the minimum drag, $\mathrm{C}_{\mathrm{D} 0 \text {, }}$ could be specified accurately. Four model scales of $16 \%, 18 \%, 20 \%$, and $22 \%$ were considered. Although a $20 \%$ scale model size was deemed to be feasible, a more conservative approach pointed to the $18 \%$ scale as having a lower risk of encountering tunnel interference effects.

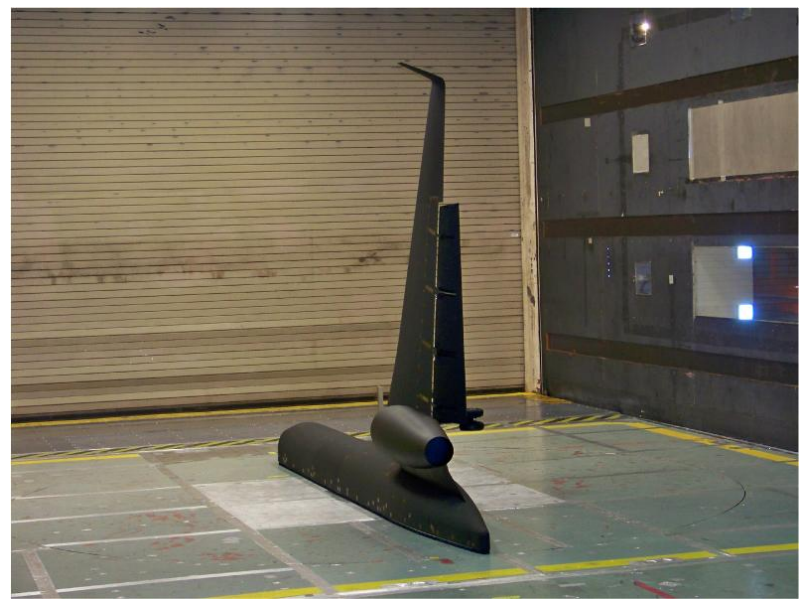

a) Installed in NASA LaRC $14 \times 22$ tunnel

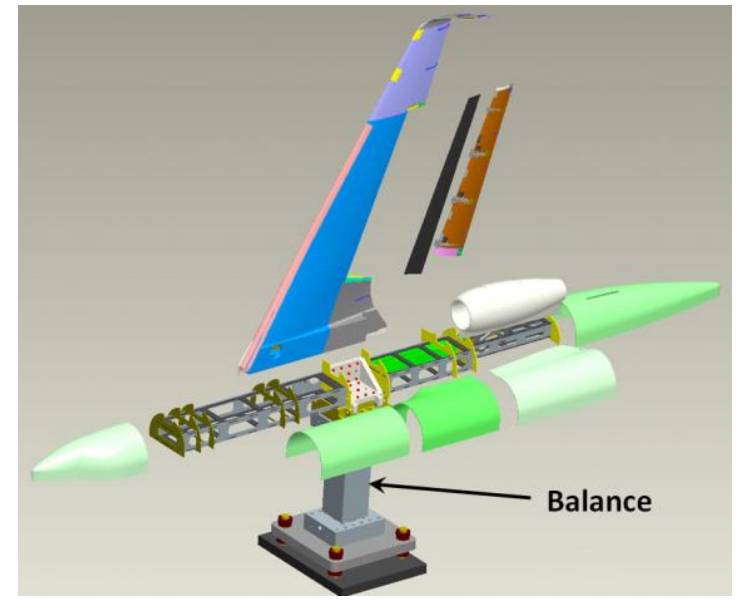

b) Exploded view of model

Figure $1.18 \%$ scale semi-span model of a Gulfstream aircraft.

\section{B. Model Components}

The model geometry comprises a fuselage, wing, flap, flow-through nacelle, pylon, and main landing gear. The five segment fuselage is made of a light weight composite skin attached to an aluminum skeleton for structural support (Fig. 2a). From nose to tail, the model is $185.4 \mathrm{in}(4.709 \mathrm{~m})$ long. To minimize the influence of tunnel floor boundary layer on aerodynamic measurements, the fuselage profile at the symmetry plane was extended in a twodimensional fashion (Fig. $2 \mathrm{~b}$ ) by 3 in $(7.62 \mathrm{~cm})$, followed by 0.5 in $(1.27 \mathrm{~cm})$ long nylon brush seals to prevent flow seepage under the model.

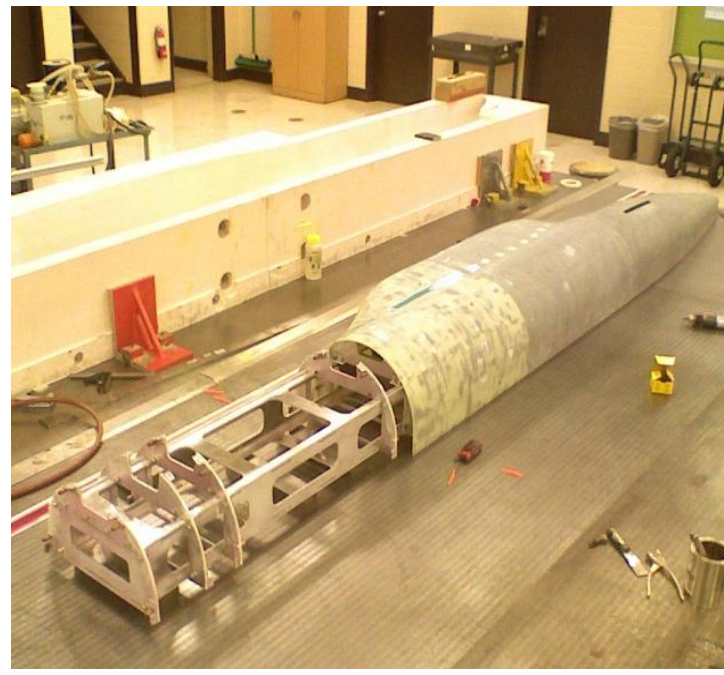

a) Aluminum ribs supporting composite skin

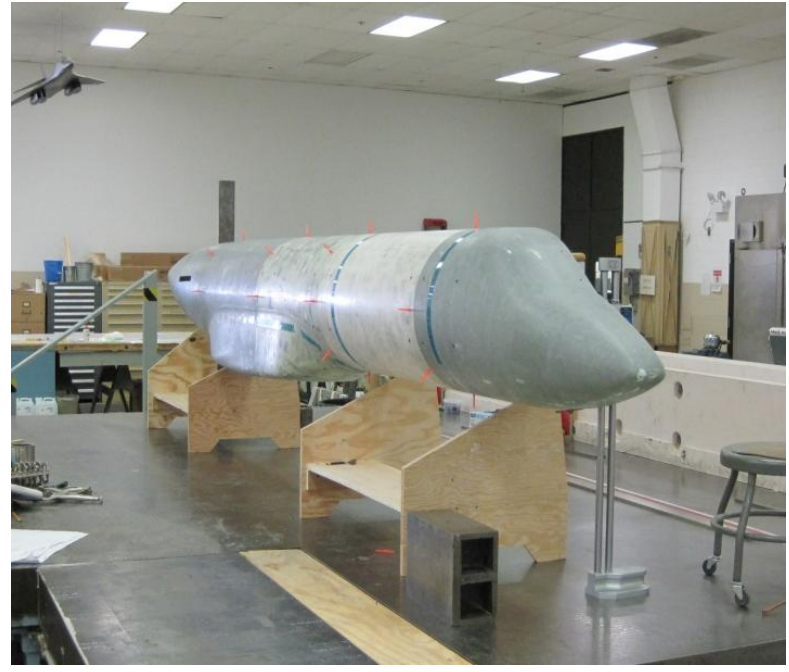

b) All five skin segments assembled

Figure 2. 18\% scale semi-span model fuselage. 
The powerplant is represented by a flow-through nacelle and the supporting pylon. Both subcomponents are made from multiple segments of polycarbonate material (see Fig. 3) using a rapid prototyping process. The polycarbonate pylon was designed as a hollow piece containing an aluminum plate that is bolted on one side to the fuselage ribs and on the opposite side to the nacelle. The rough surfaces were hand worked to obtain a relatively smooth finish. No attempt was made to measure the surface finish on the nacelle or the pylon.

The wing is made of multiple aluminum segments. The wing span (measured from the wind tunnel floor to the tip of the winglet) is 104.5 in $(2.654 \mathrm{~m})$. To accommodate the large number of pressure orifices, a significant portion of the wing volume was designed to be hollow. A large door on the bottom of the wing provides easy access to the pressure tubes and other internal instrumentation hardware. An exploded view of the wing from the bottom side is shown in Fig. 4, displaying some of the intricate details of the various subcomponents. The wing profile required a tight tolerance of 0.005 in $(0.127 \mathrm{~mm})$ near the wing leading and trailing edges and 0.010 in $(0.254 \mathrm{~mm})$ everywhere else. Postmachining Quality Assurance (QA) of the wing

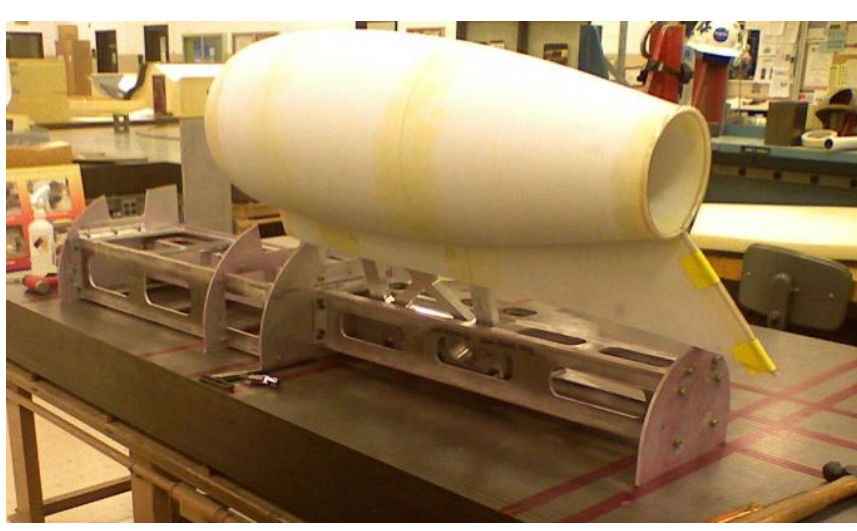

Figure 3. Flow-through engine nacelle and pylon bolted to aft fuselage skeleton. showed that the desired accuracy had been attained. The specified wing surface finish was 64 micro inches RMS (root-meansquare value) or better, which was maintained during the machining process.

By far, the flap is the most intricate component of the $18 \%$ Gulfstream model. The flap is both swept and tapered. Measured along its trailing edge, it is 55.17 in $(1.401 \mathrm{~m})$ long with a maximum thickness of 1.36 in $(3.45 \mathrm{~cm})$, which occurs at the inboard edge. The dual requirements of high geometric fidelity and extensive instrumentation of the flap surfaces made its design an extremely challenging task. To accommodate the instrumentation, most of the flap volume had to be divided into a series of cavities with complex passages at

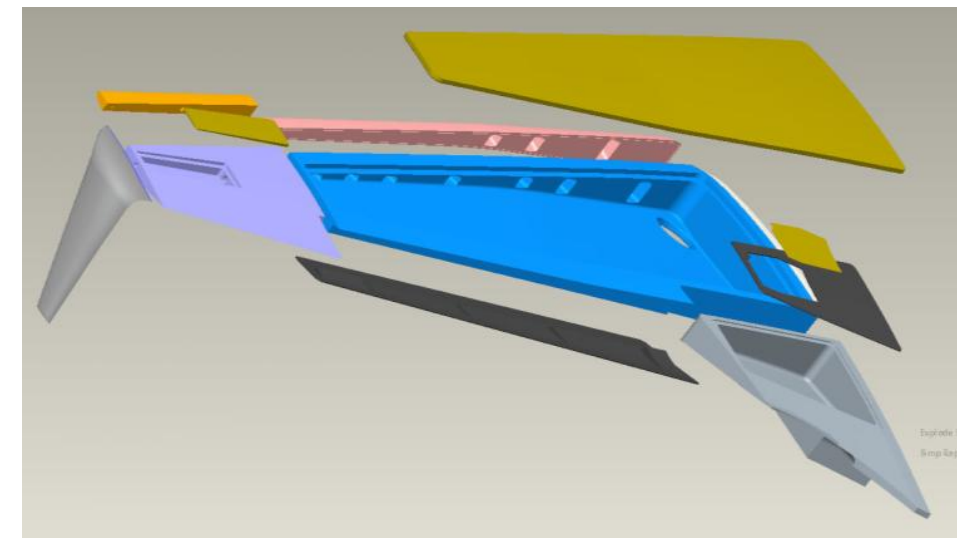

Figure 4. Exploded bottom view of wing. the leading edge and tips. The thin-walled, clam shell structure of the flap necessitated making this component from high strength steel, dramatically increasing the fabrication time and cost. A tight tolerance of 0.005 in $(0.127 \mathrm{~mm})$ was specified for the entire flap contour. Post-fabrication QA of the flap revealed that the desired accuracy had been achieved. The specified flap surface finish was 64 micro inches RMS or better. An exploded top view of the flap, showing all the relevant subcomponents, is displayed in Fig. 5. For the Gulfstream aircraft flap, the brackets and the associated flap tracks reside on the top side. Moreover, the flap tips (also referred as flap side-edges) have been designed in a modular fashion to allow evaluation of various tip treatments aimed at reducing flap noise. 


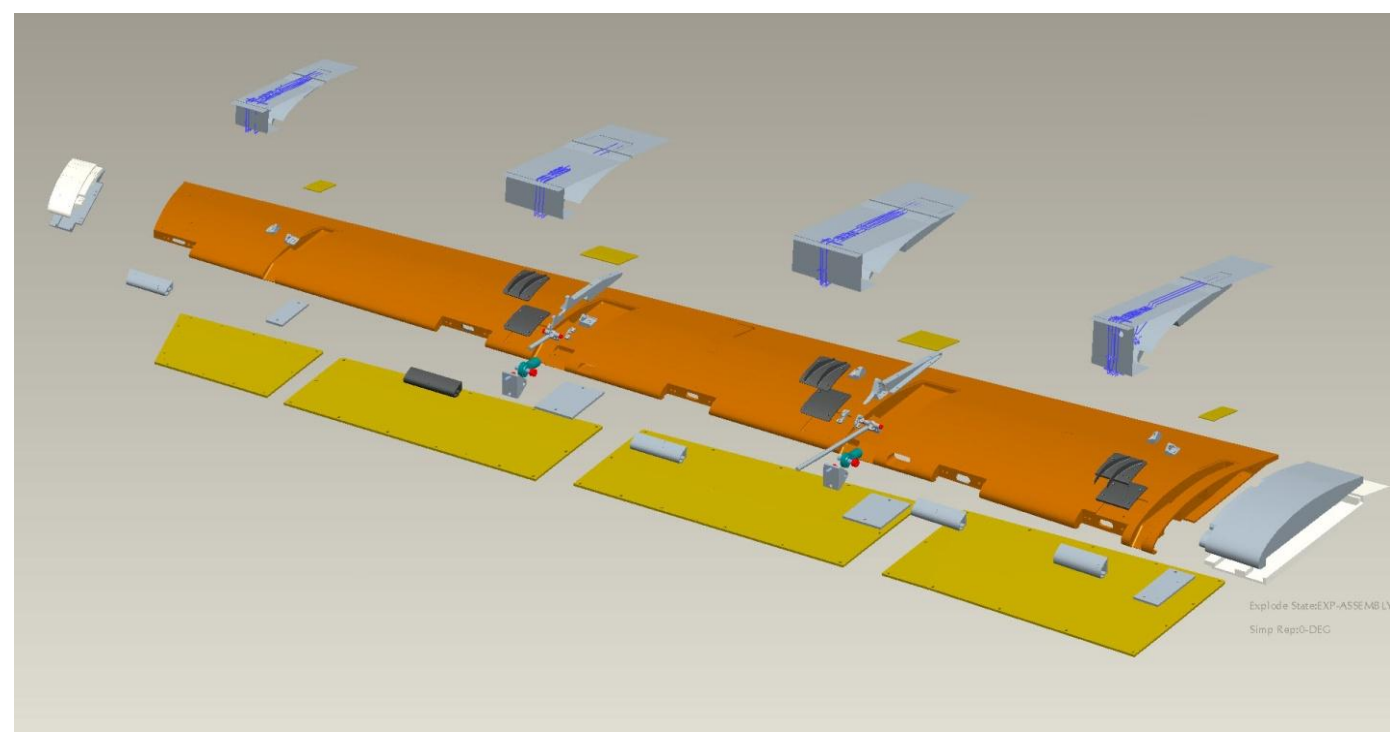

Figure 5. Exploded top view of flap.

Design and fabrication of the main landing gear was also a challenge. Again, the multitude of constraints associated with replicating some of the finest geometric details (e.g., brake system, hydraulic and electrical lines, etc.) and with managing the extensive instrumentation made the fabrication and integration of the main landing gear an expensive and time consuming task. Figure 6 presents an exploded view of the landing gear, showing some of the larger subcomponents including the gear cavity and door. Most of the landing gear components were made using rapid prototyping processes-Fused Deposition Modeling (polycarbonate material) or Direct Metal Sintering (stainless steel powder). However, some of the larger and geometrically simpler components were fabricated using standard machining practices. No attempt was made to attain extremely smooth gear surfaces. Although slightly rough coming out of the rapid prototyping process, most of the surfaces were accepted as they were. Nevertheless, care was exercised to ensure that those surface areas that were deemed to be excessively rough were manually smoothed.
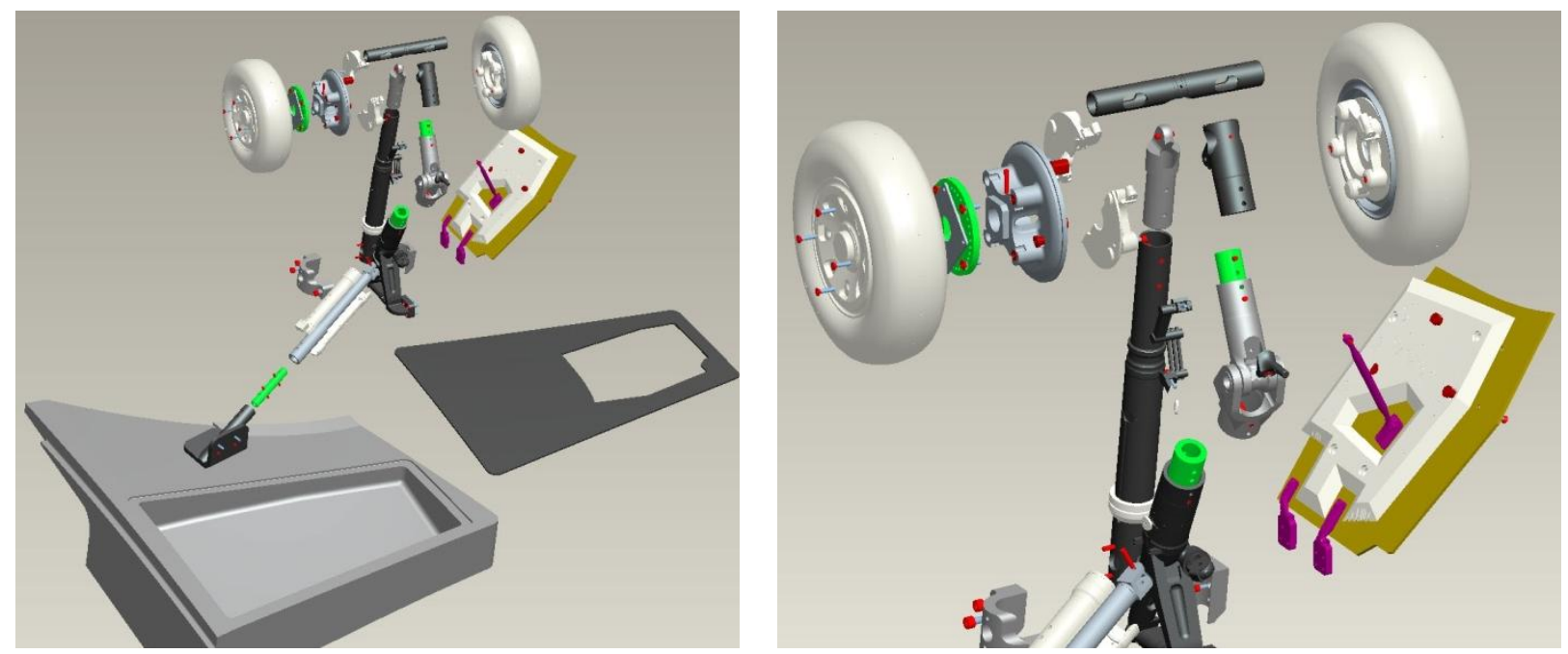

Figure 6. Exploded global and expanded views of main landing gear.

After model integration, QA of the assembled model for locations of the steady and unsteady pressure ports (nearly 650 points) on the wing and flap was performed. Except for a small number (five or six), the "as built" pressure port locations were all within the specified tight tolerances. 


\section{Model Instrumentation}

To gain insight into the principles of airframe noise generation and to help validate/advance computational simulation tools, extensive steady and unsteady, on-surface and off-surface flow, as well as acoustic measurements, must be acquired. Although the present paper is focused on steady measurements, other aspects of the instrumentation are provided here for completeness. The majority of model components were heavily instrumented with static surface pressure orifices to measure, in addition to global forces (lift, drag, etc.), some of the more complex flow features that create noise. As prominent noise sources, the flap inboard and outboard tips and the various components of the main landing gear were populated with a significant number of miniature unsteady pressure sensors. In total, 758 static pressure ports with $0.020 \mathrm{in}(0.5 \mathrm{~mm})$ inner diameter, 69 dynamic pressure transducers, and 12 accelerometers were installed on the model. An account of the static port distribution on various components is provided below. A detailed description of unsteady sensor placement is given in the companion paper by Khorrami and Neuhart. ${ }^{11}$

Of the total static ports, 345 were installed on the wing in eight full rows, two partial rows, and two full rows on the winglet. For the full rows, more than a third of the orifices were concentrated near the leading edge region to resolve the flow attachment locations and suction peaks. This was the best resolution that could be achieved given the small radius of curvature at the leading edge. Figure 7 displays a top view of the spanwise location and numbering of the wing pressure rows. Rows numbered 2 and 8 are partial rows with ports located at the wing edges adjacent to the flap tips. Note in Fig. 7a that the wing pressure rows extend over the darker color area that overlaps the stowed flap top surface. This darker region represents the wing spoiler, which was treated as part of the wing for instrumentation purposes.

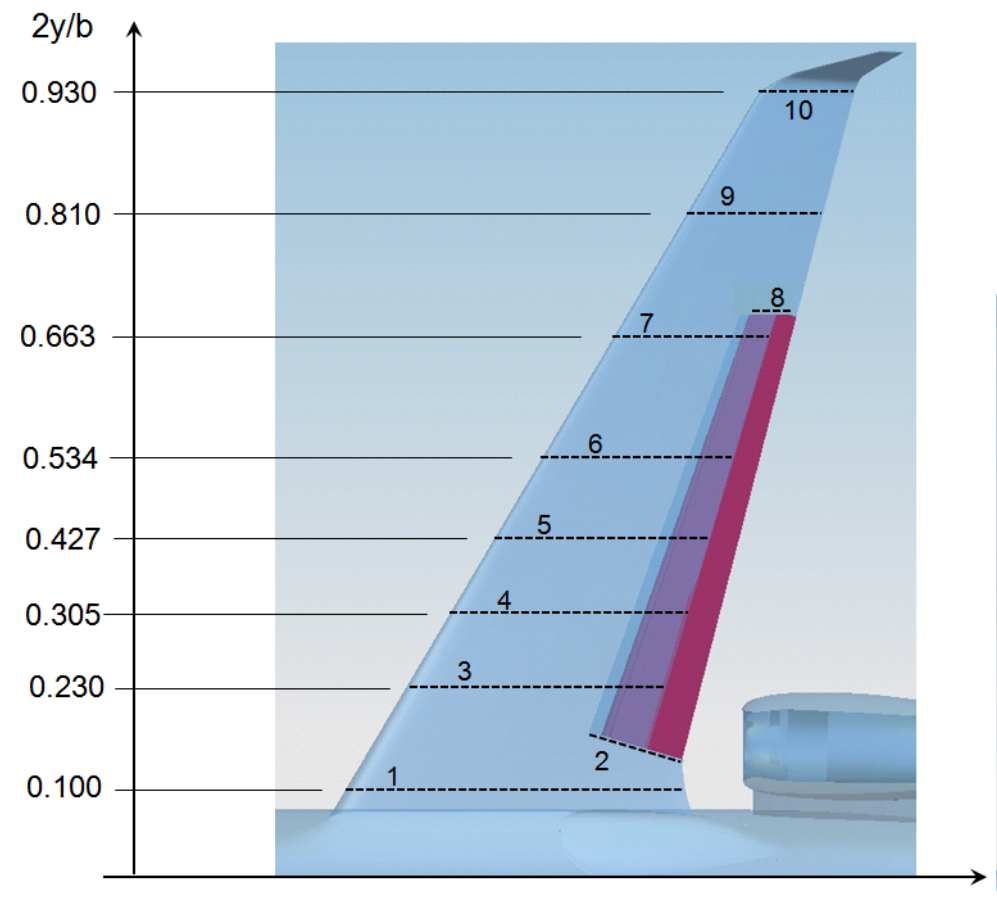

a) Wing

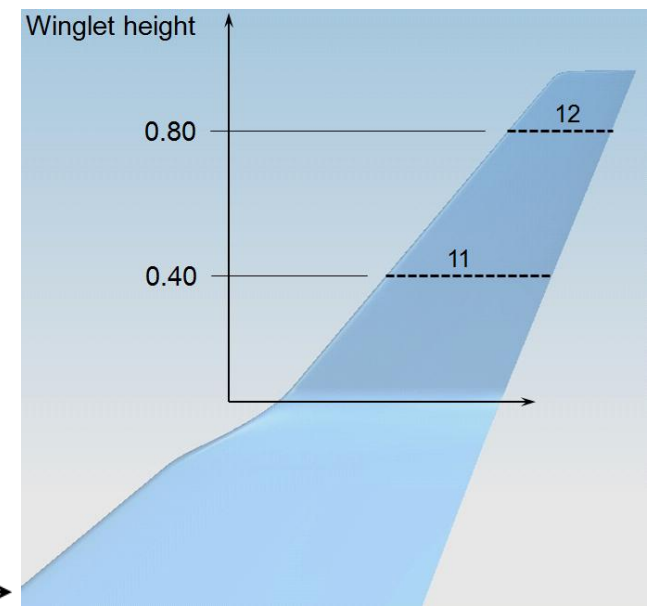

b) Winglet

Figure 7. Spanwise location and identification number for rows of static pressure orifices.

The flap possesses 254 pressure ports unevenly distributed among eleven rows (see Fig. 8). To resolve the finer details of the surface pressure features at the flap inboard and outboard tips, a larger number of orifices were accommodated in rows 1,2 , and 11 . To substantially reduce the number of pressure tubes that had to be routed from the flap to the wing, four 64-port Scanivalve pressure modules (ZOC22b model) were implanted inside the flap cavities. Also contained inside these cavities are the electrical wiring, inline amplifiers, and temperature compensators for some of the 41 dynamic pressure sensors and 2 accelerometers. Figure 9 is a partial bottom view of the flap cavities showing the instrumentation wiring and tubing. 

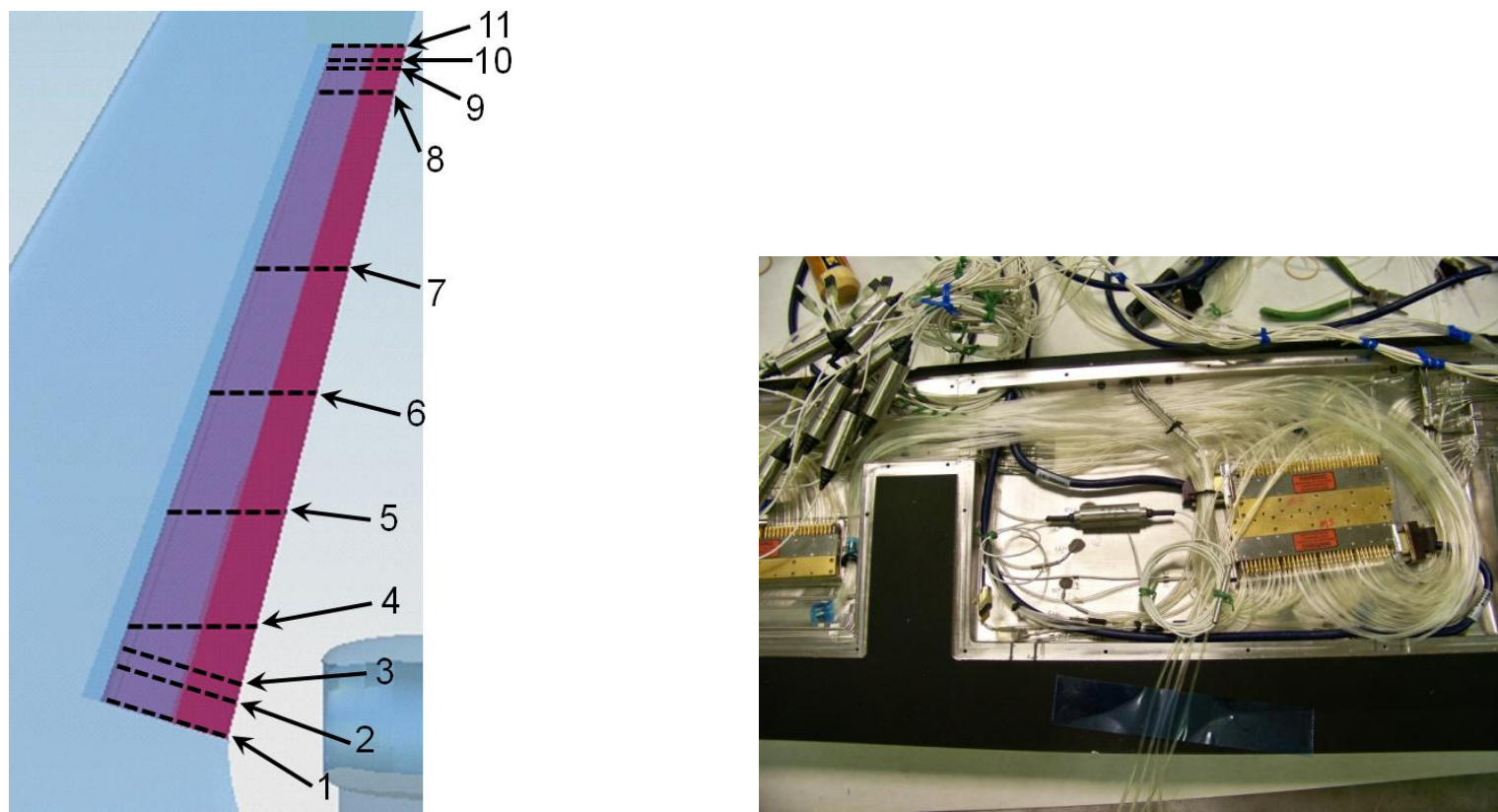

Figure 8. Flap orifice row distribution and numbering. Figure 9. Flap bottom view showing instrumentation.

There were 105 static orifices installed on the main landing gear. The distribution of ports on the various subcomponents is as follows: 32 on each wheel, 23 combined on the two main struts, and 18 on the door. The ports on each wheel are arranged in one circumferential row placed in the middle of the tire and in two transverse rows at $110^{\circ}$ and $180^{\circ}$ as shown in Fig. 10. The wheels are designed to be rotated $\pm 30^{\circ}$ in $10^{\circ}$ increments to increase the span of surface pressure measurements on the tires. In addition to the static ports, 29 unsteady pressure transducers were installed on the gear: 12 on the wheels, 7 on the two main struts, and the remaining 10 on the door. Also, 2 accelerometers were housed inside the gear, one in each wheel, to measure vibration. As was the case for the flap, the need to accommodate this level of instrumentation on the main gear placed a severe challenge on routing the associated tubing and wiring. To eliminate the need to route the 64 static pressure tubes for the wheels through the rear strut, two 32-port Pressure Systems ESP (Electronically Scanned Pressure) modules (32HD model) were implanted inside the tires, one in each side.

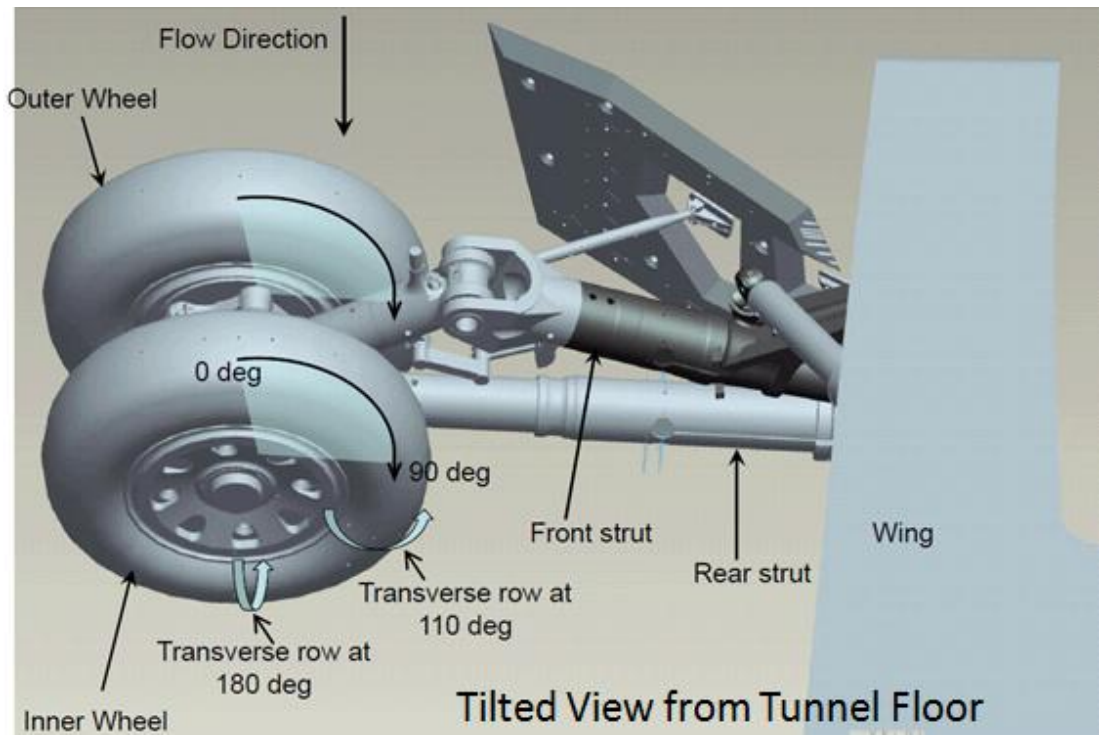

Figure 10. Static pressure orifices on the main landing gear. 
There are 54 pressure ports on the fuselage, arranged in two circumferential rows (rows 1 and 2) and one nearly streamwise row (row 3 ) that is intended for capturing wing-body juncture effects (see Fig. 11).

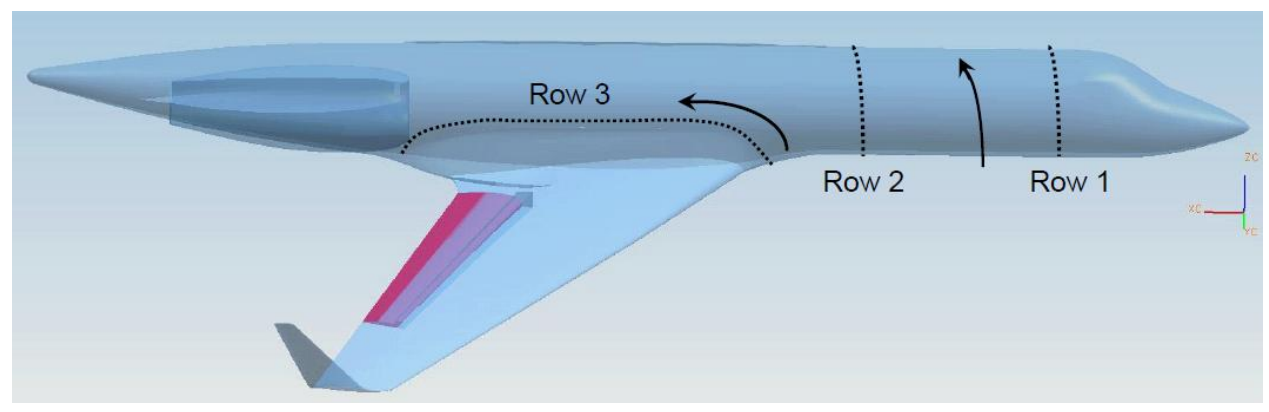

Figure 11. Static pressure orifices on the fuselage.

To obtain accurate measurements of lift and drag, the semi-span model was designed to couple with the NASA LaRC VST-8 strain gauge balance (see Fig. 1b). The normal force on the VST-8 has a capability of 5,000 pounds and an accuracy of $0.23 \%$ full scale. Because of the way the model was mounted, the model axial force was actually measured by the side force of the balance. The VST-8 side force has a capability of 1,500 pounds and an accuracy of $0.16 \%$ full scale.

\section{Results}

The first entry into the LaRC 14x22 tunnel was completed November 2010. This test was devoted entirely to the aerodynamic characteristics of the model. Configurations of $39^{\circ}, 20^{\circ}$, and $0^{\circ}$ flap deflections with the main landing gear on and off were tested at Mach numbers of 0.16, 0.20, and 0.24. Additionally, for each flap deflection, the model was tested with the $14 \times 22$ tunnel in both the closed-wall and open-wall (jet) modes. Given the specific interest in airframe noise during landing operations, the $39^{\circ}$ flap setting was the initial and most heavily tested configuration of the experiment. Therefore, results for this baseline setting at Mach 0.2 with the tunnel in the close-wall mode are the focus of the present paper.

\section{A. Test Conditions}

Most of the data were taken for a nominal Mach number of 0.20. At this Mach number, the tunnel dynamic pressure, Q, and the freestream speed are $58 \mathrm{psf}(2.77 \mathrm{kPa})$ and $223 \mathrm{ft} / \mathrm{sec}(68 \mathrm{~m} / \mathrm{sec})$, respectively. The corresponding Reynolds number is 1.33 million per foot (4.40 million per meter) resulting in a value of 3.40 million based on the $18 \%$ model mean aerodynamic chord of 30.8 " $(0.782 \mathrm{~m})$. Based on a previous study ${ }^{13}$, the freestream turbulence level in the $14 \times 22$ tunnel (in the closed-wall configuration) typically ranges between $0.05 \%$ and $0.09 \%$, and at this condition was measured at $0.07 \%$. With the tunnel in the open wall (jet) configuration, the levels are substantially higher and approach $0.25 \% .^{14}$

\section{B. Boundary Layer Trips}

Aerodynamic testing commenced without any transition strips applied to the model. This was done to determine whether aerodynamically, at $18 \%$ of scale, the model exhibits a low or high Reynolds number (Re) behavior. While variation of the lift coefficient $\left(\mathrm{C}_{\mathrm{L}}\right)$ versus angle-of-attack (alpha) displayed high Re behavior, closer scrutiny of the state of the wing leading edge boundary layer indicated that some improvement in the $C_{L}$ behavior near stall may be possible by tripping the wing boundary layer. This state was determined by employing Napthalene sublimation. The chemical, dissolved in a solvent and sprayed on the model surface, manifested as a thin, white coating. As the tunnel was brought up to the desired flow condition, the chemical coating under turbulent flow exhibited higher heat transfer rates and skin friction, facilitating faster sublimation of the chemical. The resulting contrast between the areas of turbulent and laminar flow (i.e., dark and light areas, respectively) indicated the extent of laminar flow over the model. Based on a series of trials, the size and location of the boundary layer trips was determined so that fullyturbulent, full-scale flow conditions over the wing surface could be simulated.

The boundary layer on the bottom surface of the wing was tripped from the root to the tip at a streamwise location corresponding to $9.5 \%$ of the local chord. The trip was comprised of a series of trip dots having a diameter of 0.1 in $(2.5 \mathrm{~mm})$. The wing span was divided into three equal segments with trip dots having heights of 0.008 in 
$(0.203 \mathrm{~mm}), 0.007 \mathrm{in}(0.178 \mathrm{~mm})$, and 0.006 in $(0.152 \mathrm{~mm})$ applied to the inboard (adjacent to the wing root), middle, and outboard (wing tip) segments, respectively.

For the top surface of the wing, starting from the root, the trip dots were applied only to the first 69 in $(1.75 \mathrm{~m})$ along the leading edge. The dots were positioned at $2.5 \%$ of the local chord, slightly upstream of the location where peak suction occurs. Three equal segments of transition dots with heights of 0.006 in $(0.152 \mathrm{~mm}), 0.005$ in $(0.127$ $\mathrm{mm})$, and 0.0045 in $(0.114 \mathrm{~mm})$ were applied on the top surface. Tripping the outer $33 \%$ of the wing span proved to be detrimental to the lift and resulted in early stall. Therefore, a decision was made to forgo forced transition and allow the boundary layer to develop naturally for the outer portion of the wing span.

\section{Flap 39 ${ }^{\circ}$ (Baseline) Configuration}

The measured lift $\left(\mathrm{C}_{\mathrm{L}}\right)$ and drag $\left(\mathrm{C}_{\mathrm{D}}\right)$ coefficients for the baseline configuration are plotted in Fig. 12. Included in the plots are data provided by Gulfstream Aerospace Corporation (GAC) from their 5.6\% scale full-span model and full-scale (flight) tests. The lateral offset in the $\mathrm{C}_{\mathrm{L}}$ curves arises from comparing untrimmed model scale data to trimmed flight data. Also, included in this offset are the tunnel wall effects. Thus, the fact that the lift slopes corresponding to the $18 \%$ model and full-scale data are nearly identical (in the linear regime) is a mere coincidence. This is one of those rare occasions where the tunnel wall plus the missing horizontal tail effects have caused the 18\% model lift slope to mimic the free-air flight data. We will revisit this point shortly.

In Figure 12a, notice that the lift curve for the 5.6\% scale model deviates from a linear behavior at relatively low angles of attack, followed by a gradual loss of lift (stall) that persists over a large angle range. These two characteristics are classical manifestations of low Re behavior. In contrast, the lift distribution for the $18 \%$ scale model captures nearly the full extent of the linear regime followed by the appearance of an abrupt stall condition that is typical of high Re behavior of wings in high-lift configurations. A plausible cause for the difference in $\mathrm{C}_{\mathrm{Lmax}}$ between flight and the $18 \%$ scale model is Re effects, and to a lesser extent, aeroelastic effects (videogrammetry was used during the test to obtain an estimate of the maximum wing-tip deflection).

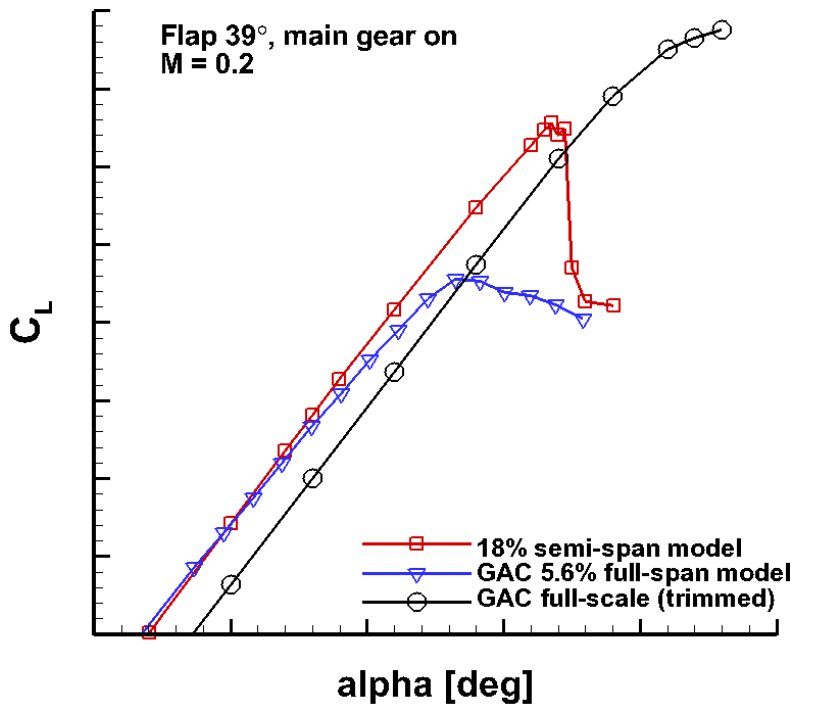

a) Lift coefficient

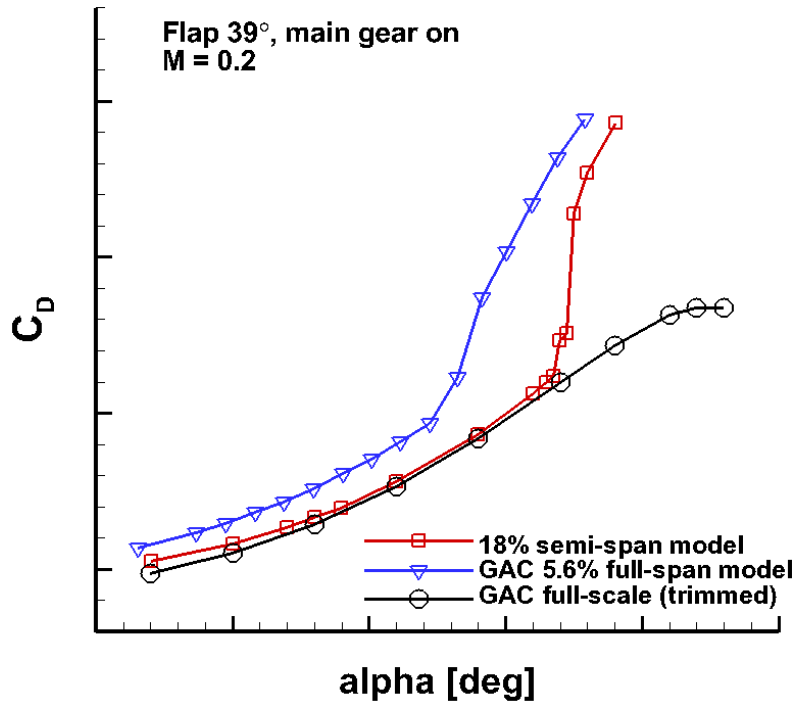

b) Drag coefficient

Figure 12. Variation of lift and drag coefficients with angle-of-attack.

The behavior of $C_{D}$ with increasing alpha for the two models and flight test is shown in Fig. 12b. The full-scale values were obtained using the quadratic equation $C_{D}=\mathrm{k} \mathrm{C}_{\mathrm{L}}^{2}+\mathrm{C}_{\mathrm{D} 0}$. The constants, $\mathrm{k}$ and $\mathrm{C}_{\mathrm{D} 0}$, were provided by Gulfstream Flight Sciences Engineering. Again, the 5.6\% scale model displays typical low Re behavior-its $C_{D}$ is much higher than, and deviates early from, that of the full scale aircraft. The drag for the $18 \%$ scale semi-span model tracks closely the flight data variation, rising dramatically when stall is encountered.

We now return to Fig. 12a and the issue of trimmed flight data versus untrimmed wind tunnel model measurements. To demonstrate that the $18 \%$ model lift coefficient closely tracks the full-scale data required two separate corrective steps executed serially. The first step involved accounting for tunnel wall interference effects using classical wall corrections that take into account solid/wake blockage and general downwash. ${ }^{15}$ The resultant lift and pitching moment coefficients represent the untrimmed free-air values. In the second step, neglecting higher order 
effects, the wall corrected pitching moment coefficient was used to determine the lift coefficient associated with the horizontal tail to maintain a zero pitching moment. The trimmed lift coefficient for the $18 \%$ model is plotted in Fig. 13. Also included in the plot is the lift coefficient from the intermediate step when only the tunnel wall corrections are applied. The wall and trim corrected lift coefficients associated with the $18 \%$ model now closely track the fullscale values and the two datasets show a remarkable agreement over the entire linear range.

Sample plots of pressure variation over the wing and flap are shown in Fig. 14. Row 5 on the wing and Row 6 on the flap are at the spanwise location corresponding to the flap mid-span. Notice that the suction peaks for both wing and flap are captured relatively well. For airframe noise, the pressure distributions adjacent to the flap tips are of critical importance. Typically, most of the noise generated by the flaps occurs at the side edges. In most instances, the vortex roll-up process at the flap tips is quite complex, resulting in an intricate system of multiple vortices. To capture the surface imprints of the complex flow structures, static orifice rows were installed very close to the flap side edges. The pressure distributions at the flap inboard and outboard edges are plotted in Fig. 15. At both tips, peak suction occurs either at or aft of the mid-chord location. The broad suction peak is caused by the presence of a strong streamwise vortex.

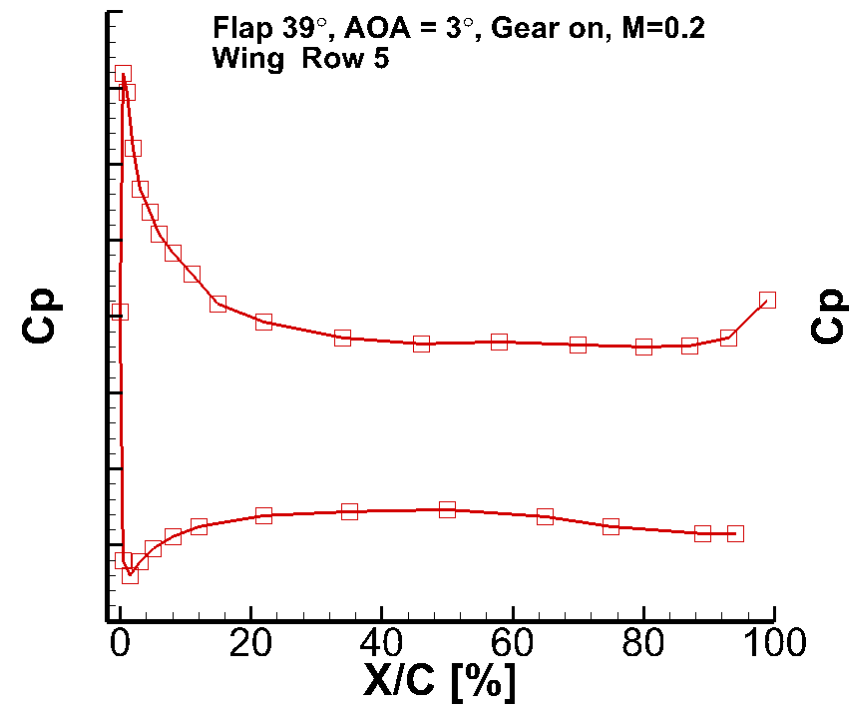

a) Row 5 on wing

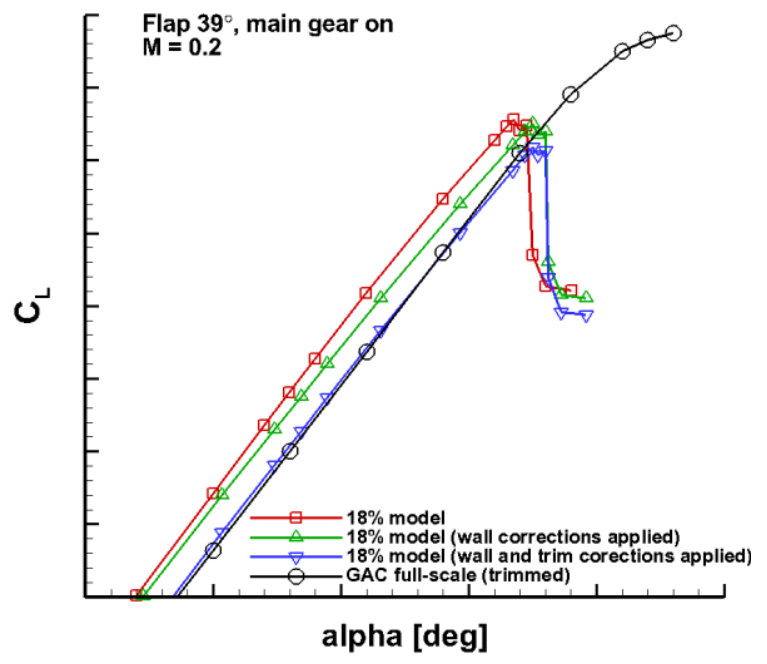

Figure 13. Corrected $C_{L}$ values for $18 \%$ model.

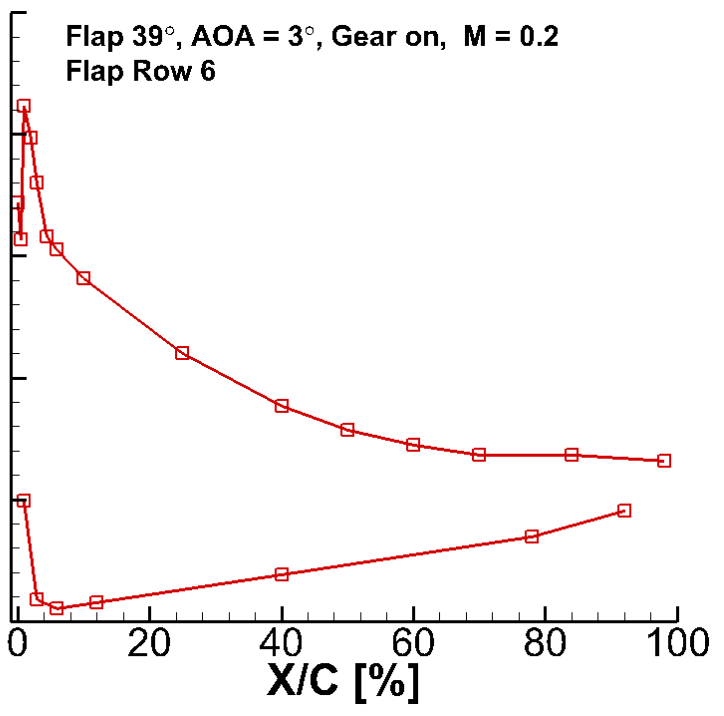

b) Row 6 on flap

Figure 14. Pressure distribution on wing and flap at a spanwise location corresponding to flap mid-span. 


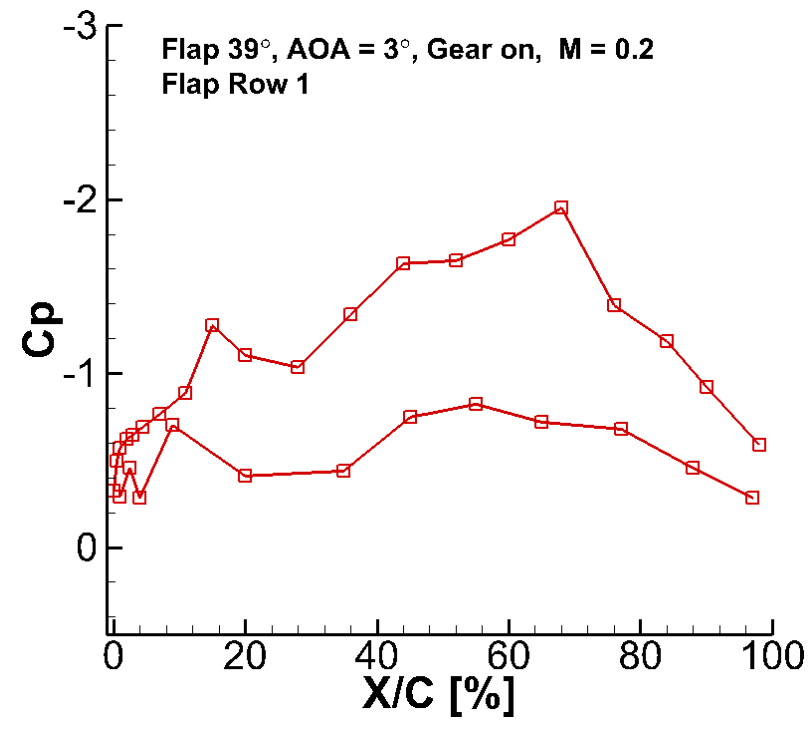

a)

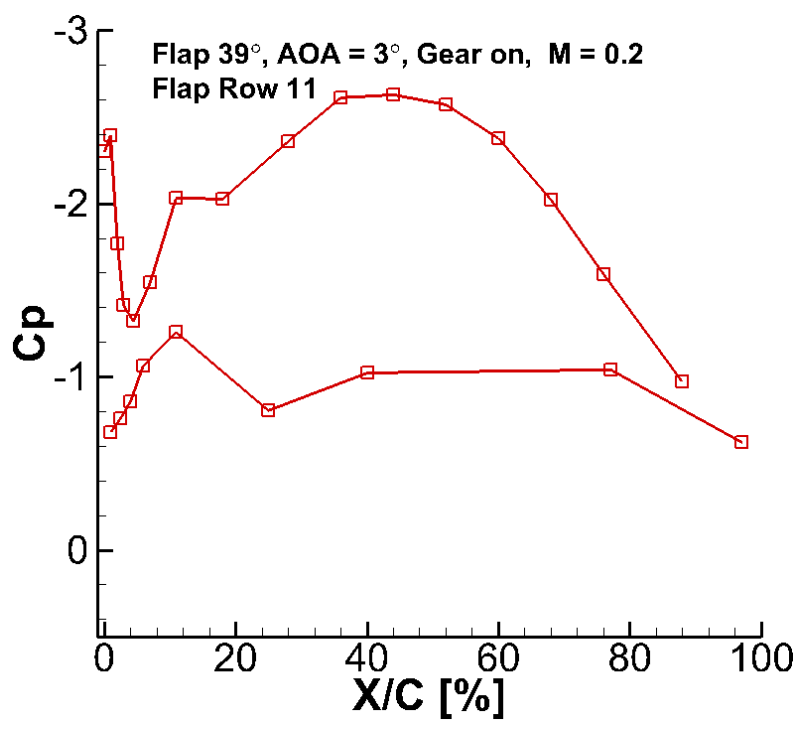

b) Outboard

Figure 15. Pressure distribution on flap close to the side edges.

As in any experiment, demonstrating data repeatability is quite important. This issue becomes even more critical when, as in the present case, the model undergoes numerous configuration changes during the test. Representative plots comparing the measured surface pressures (for the same landing configuration) from three distinct runs are shown in Figs. 16-17. In these plots, Run 45 corresponds to the pressure data already shown in Figs. 14-15. The repeat Run 53 was obtained a day later without any model configuration changes occurring between the two runs. Run 108 was a repeat run performed towards the end of the test after the model had been subjected to significant number of changes (e.g., flap deflection angles, removal and reinstallation of the main gear, etc.).

Close scrutiny of all the static pressure rows on the wing showed remarkable agreement between the three wind tunnel runs. As depicted in Fig. 16, the three datasets are virtually identical. Except for a few ports on various rows, similar good agreement between the three runs was also observed over the entire flap. The most noticeable differences occur on the bottom surface of Row 11, which is the closest row to the flap outboard edge (Fig. 17b). Given the excellent data repeatability observed at all other flap rows (not shown), it is very difficult to speculate on the cause and location of the differences. It is possible that some subtle damage may have been sustained by the model during the numerous flap changes that were executed, considering the miniature and fragile nature of the pressure tubing at the outboard edge.

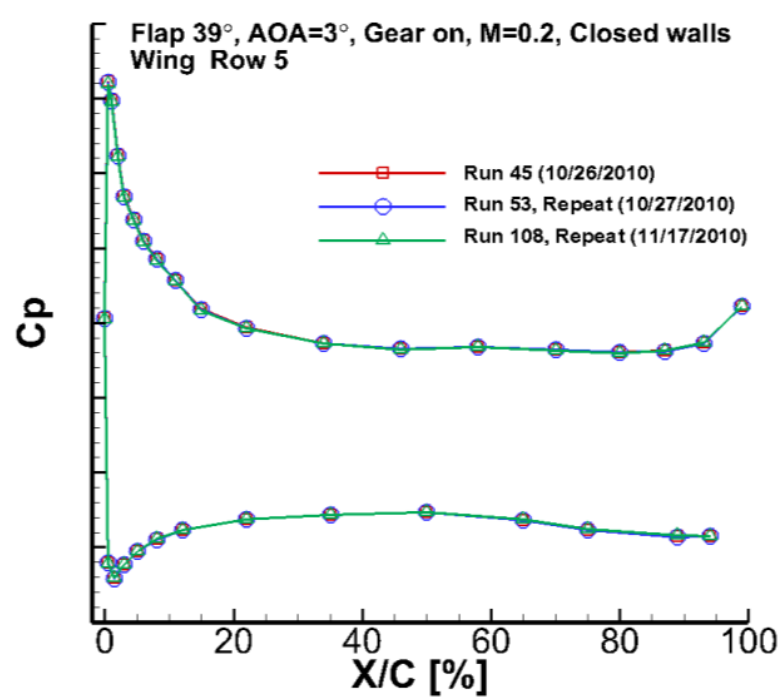

Figure 16. Sample wing pressure showing data repeatability. 


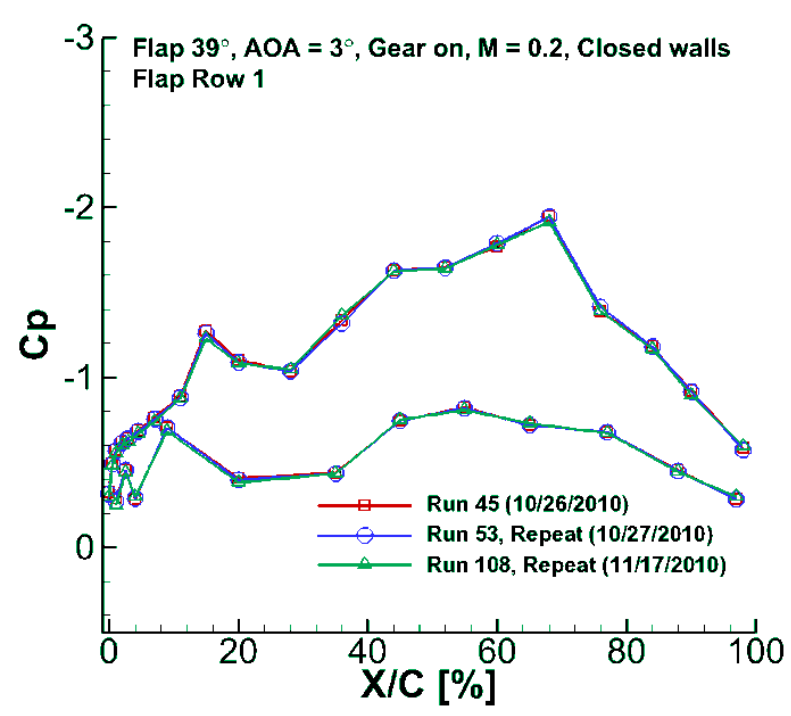

a) Inboard edge

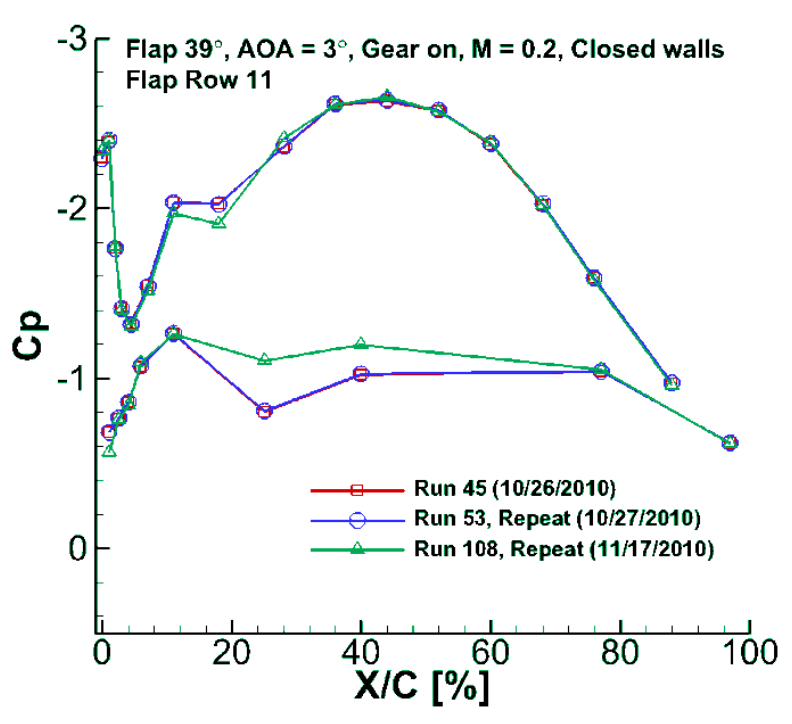

b) Outboard edge

Figure 17. Sample pressure plots showing data repeatability at the two flap edges.

\section{Main Gear Effects}

One particular component of airframe noise that has received little attention is gear-flap interaction noise. For many aircraft, the position of the main landing gear after deployment is almost coincident with the spanwise location of the flap inboard edge. The unsteady wake shed by the main gear interacts directly with the flap inboard edge, having the potential to generate noise. To assess the effect of the gear on the aerodynamic behavior of the model, the main landing gear was removed and the cavity sealed. The variation of lift and drag with angle of attack for the $18 \%$ model with and without the main gear is shown in Fig. 18. As suspected, gear removal (retraction) has little effect on the global lift distribution. There are few noticeable differences between the lift curves for the two configurations up to model stall. As expected, there is a clear decrease in model drag at all angles when the gear is off-the bluff body components of landing gear are known to be high-drag producers.

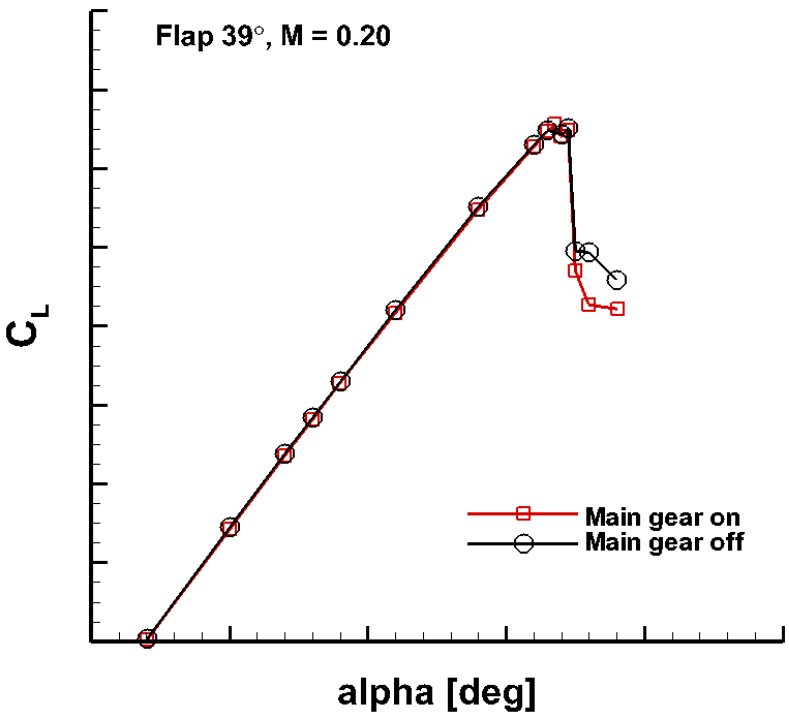

a) Lift coefficient

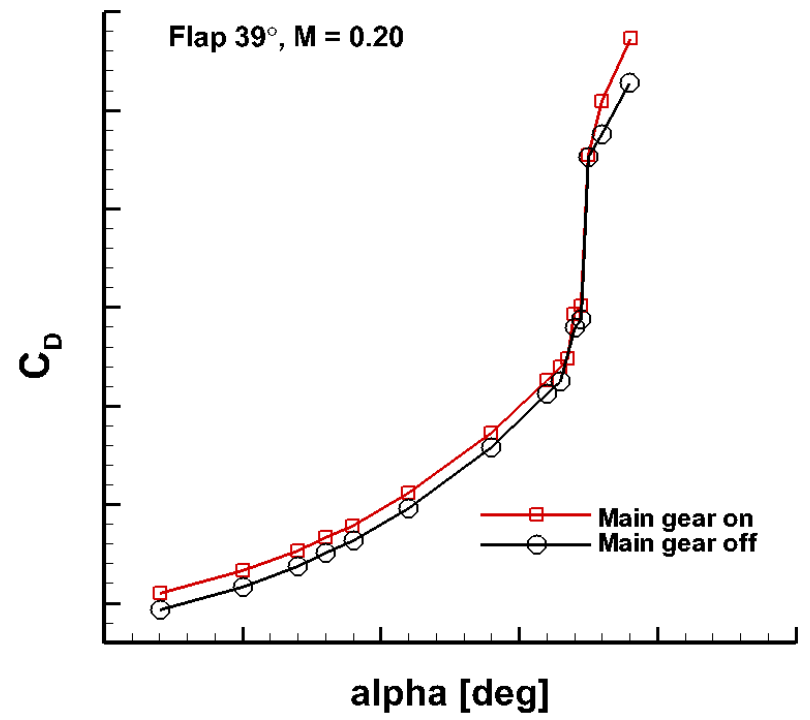

b) Drag coefficient

Figure 18. Aerodynamic effects of main landing gear retraction. 
Although the effects of gear on the integrated lift coefficient are small, the local effects are very important to airframe noise. To examine how the wake from the main gear affects the flap inboard edge flow field, Cp distributions for the first two rows at the flap inboard edge are plotted in Fig. 19. Notice that the gear has a profound effect on the inboard tip loading. Given the larger pressure difference when the gear wake is not present, vortex roll-up at the inboard edge should be much cleaner resulting in vortices that are noticeably stronger. Also observe that, unlike the gear-on configuration, a well defined attachment region develops near the flap leading edge. At the second row (Fig. 19b), which is 1.6 flap thicknesses away from the inboard edge, the increase in vortex suction is quite apparent. Although not shown, the effects of gear removal on the local pressure field diminish rather quickly as the sampling row moves inward from the edge.

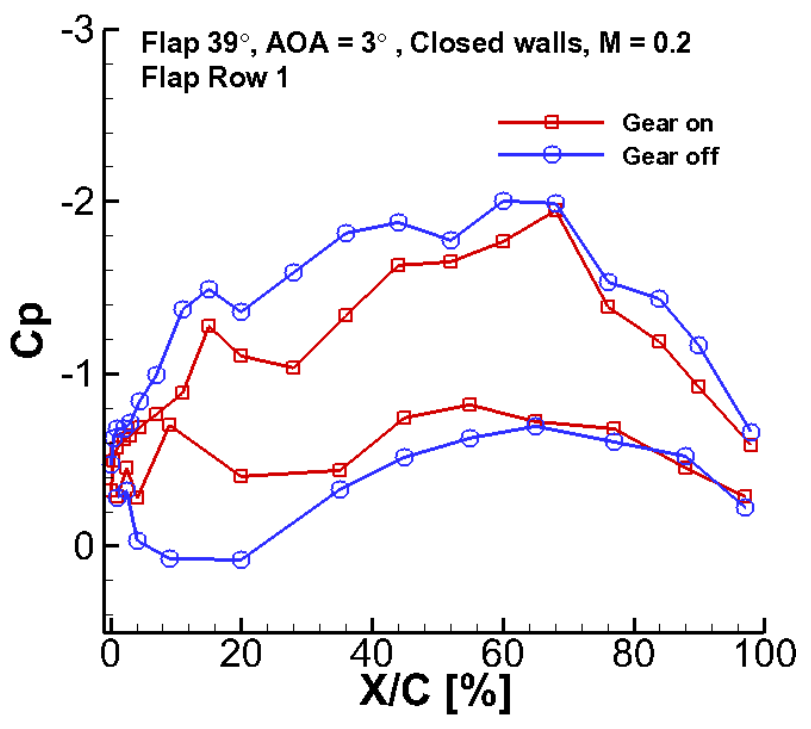

a) First row from the edge.

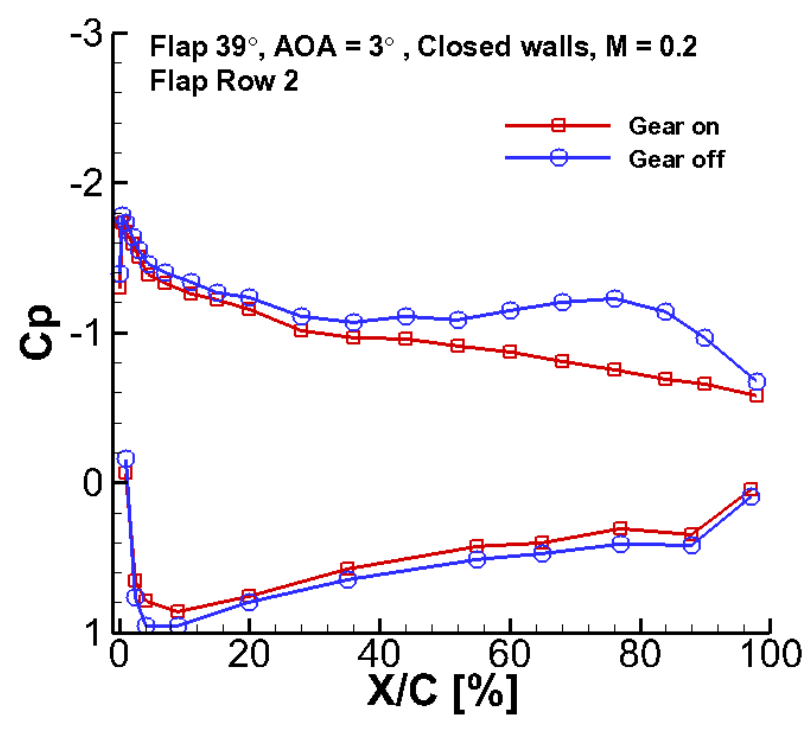

b) Second row from the edge.

Figure 19. Effect of main gear removal on the pressure distribution at the inboard edge.

\section{E. Reynolds (Mach) Number Effects}

Reynolds number effects are of critical concern in sub-scale model testing. It is desirable to show that the flow fields in the vicinity of the source regions are well established at $\mathrm{M}=0.20$ and remain fairly unaffected with further increases in flow speed, i.e, Re effects are negligible. To assess the influence of Re on the aerodynamic characteristics of the $18 \%$ scale model, most configurations of interest were tested at Mach numbers of $0.16(\mathrm{Re}=2.75$ million), 0.20 (3.40 million), and 0.24 (4.01 million). The lower and higher speeds were carefully selected to represent a 20\% variation from the $\mathrm{M}=0.20$ (nominal speed) and to provide a Re range that is $50 \%$ greater than that at $\mathrm{M}=$ 0.16 (note that even with this expanded range, the model Re falls significantly below the actual flight Re associated with the landing aircraft, which is on the order of 20 million). For the two lowest M, aerodynamic measurements were performed up to, and past, stall. For $\mathrm{M}=0.24$, the measurements were limited to moderate angles of attack due to the combination of maximum allowable balance load and designed critical load of the model.

Comparison of the aerodynamic data at the three measured flow speeds did not reveal any noticeable Re variations. The global forces $\left(C_{L}, C_{D}\right.$, etc.) could be collapsed onto a single curve with only minor differences at the stall condition. Similar data collapse was also observed for local pressure distributions. Given the importance of the local flow field at the flap tip regions, the pressures from the two rows closest to the inboard and outboard edges for the highest flap deflection and gear-on condition are plotted in Fig. 20. Notice that the pressure field at the two edges remains mostly unchanged with increasing speed, indicating a lack of Re dependence within the range tested. Figure 20a also indirectly demonstrates that the gear wake remains unaffected with changes in speed, because the inboard edge pressure distribution is similar for all speeds tested. The pressures measured at the flap interior rows (not shown) display a similar lack of speed dependency as that depicted in Fig. 20. However, rows 5-9 on the flap show a slight increase in peak suction at higher speeds. This increment is due to thinning of the flap boundary layer that brings the accelerating flow through the gap closer to the flap surface. 


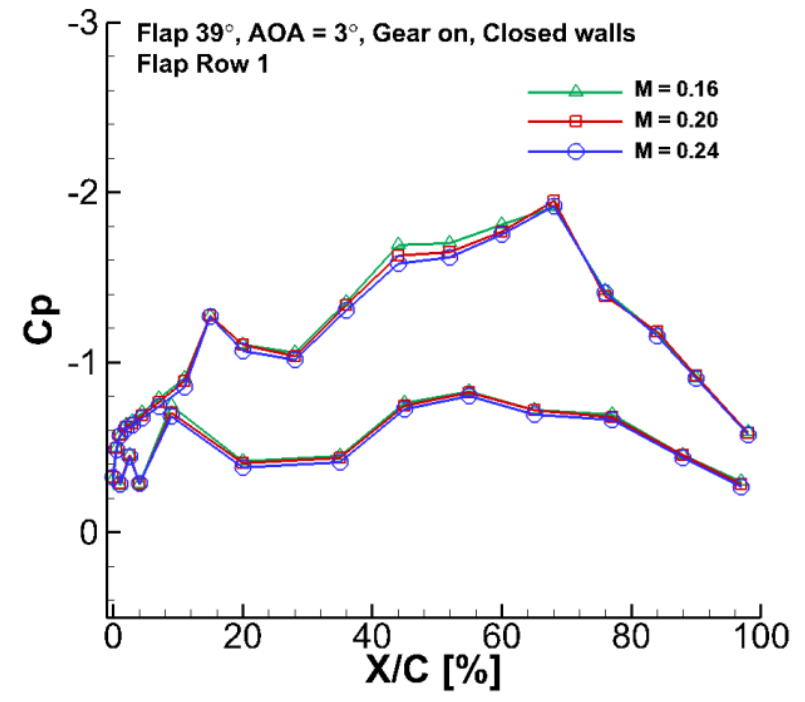

a) Inboard edge

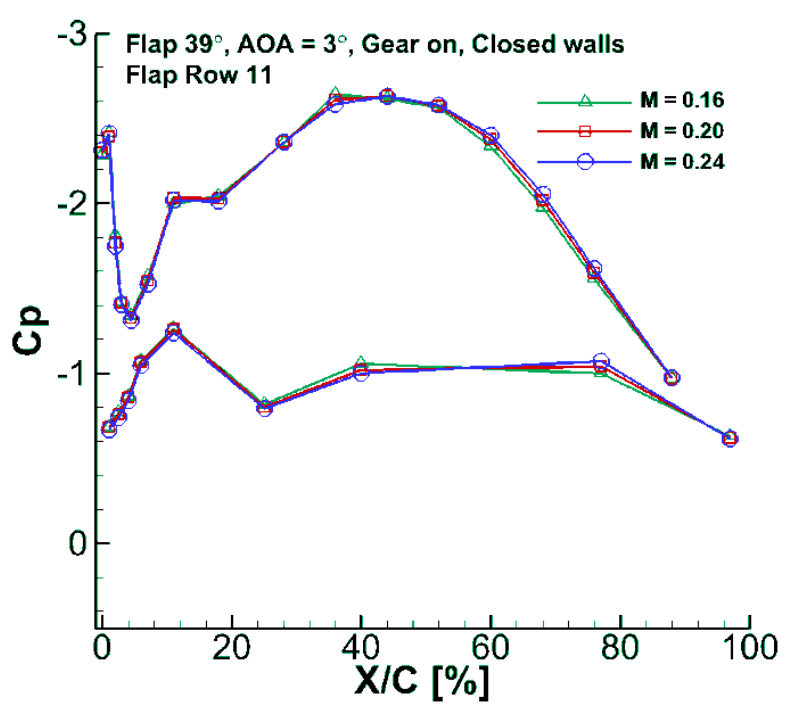

b) Outboard edge

Figure 20. Effects of Mach number variation on pressure distribution at the flap side edges.

\section{F. Closed vs. Open Walls Tunnel Configuration}

The planned acoustic and off-surface (particle image velocimetry) flow measurements require the tunnel in an open-wall (open-jet) configuration. In this mode, the reverberating effects of the tunnel walls on the acoustic field are eliminated and better optical access for the flow measurements is gained. Associated with the open-wall testing, however, is the possibility of introducing other factors that may negatively impact the aerodynamic characteristics of the model. While the model scale was selected based on conservative estimates, there was no a priori guarantee that the efficiency of the $14 \times 22$ tunnel could be maintained with walls lifted. Depending on the model size and how much lift it produces, the open jet may be deflected substantially and severely affect the performance of the model. In particular, for the present case where the high-lift aerodynamic performance through stall is desired, the impact of testing in open-wall tunnel configuration had to be carefully documented.

Comparison of lift coefficients with the tunnel in the closed- and open-wall configurations is shown in Fig. 21. The most important trend to highlight in this figure is that the character of the lift curve is preserved for angles up to, and beyond, the stall condition. As expected, the presence of the model and the lift it generated deflected the jet and reduced the effective angle of attack seen by the model in the open-wall configuration. It is well known that the corresponding lift coefficients for the free-air case would reside somewhere between the closed- and open-wall wind tunnel measurements. Included in Fig. 21 is the free-air $C_{L}$ values obtained from applying wall corrections to the closed-wall tunnel data. Notice that the corrected lift curve lies much closer to that for the open-wall tunnel. In fact, up to moderate values of alpha, there is little difference between the two curves. This behavior bodes well for the planned airframe noise and off-surface flow measurements to be conducted at low angles of attack (landing conditions) with the tunnel in open-wall mode. As indicated earlier, the lower lift levels experienced in the tunnel with walls

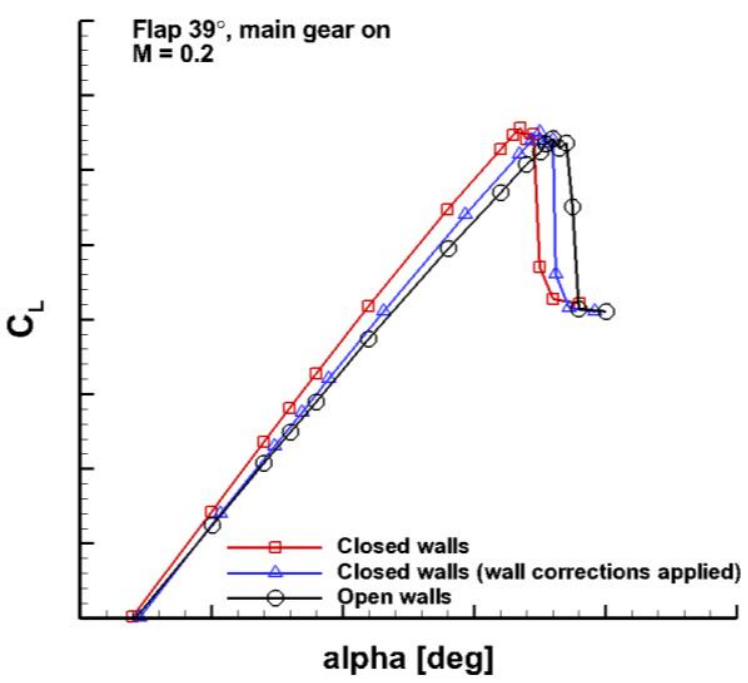

Figure 21. Tunnel configuration effects on lift coefficient. open is directly related to jet deflection and reduction in the effective angle of attack seen by the wing. To demonstrate this point, it is illustrative to examine the chordwise pressure distribution on the wing and flap. Representative pressure plots from select rows on the wing for the landing condition are displayed in Fig. 22. Notice that the closed- 
wall pressures for alpha $=3^{\circ}$ fall in between the corresponding open-wall pressures obtained at $3^{\circ}$ and $4^{\circ}$. It is also observed that most of the change in the pressure coefficients occurs on the top surface near the wing leading edge, where small variations in alpha have the potential to produce measurable changes in the suction peak. Irrespective of which wing row is considered, downstream of the mid-chord region all three curves coalesce more or less into a single curve showing no visible differences.

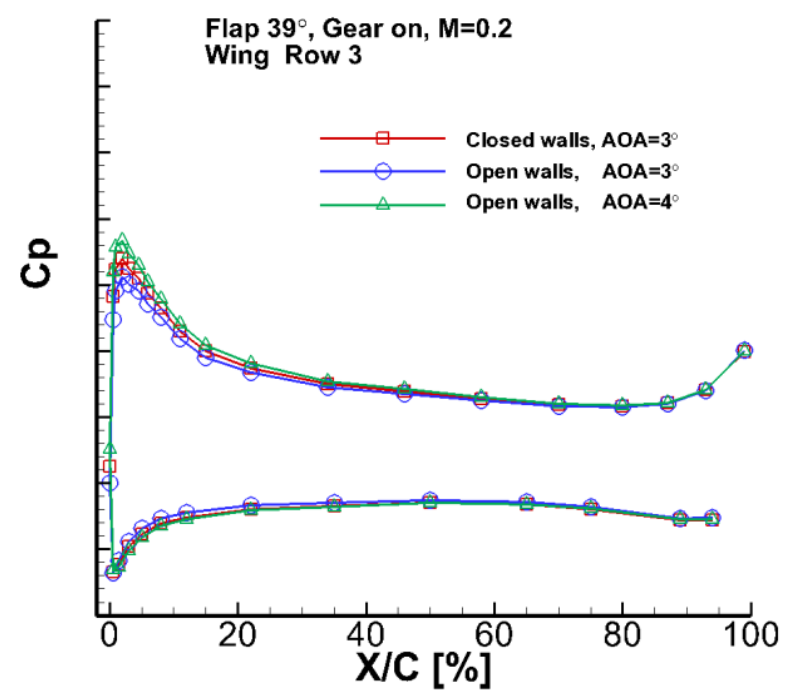

a) Wing row 3

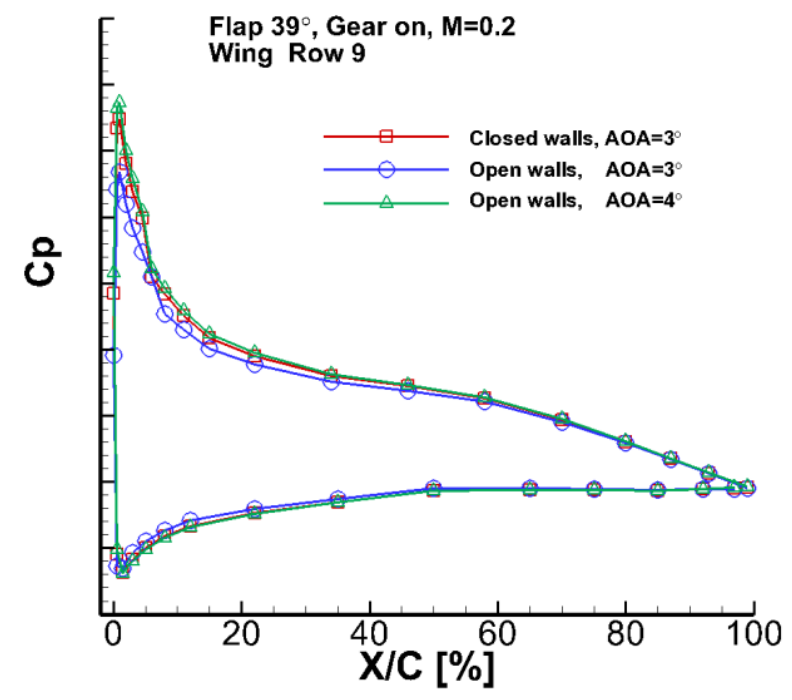

c) Wing row 9

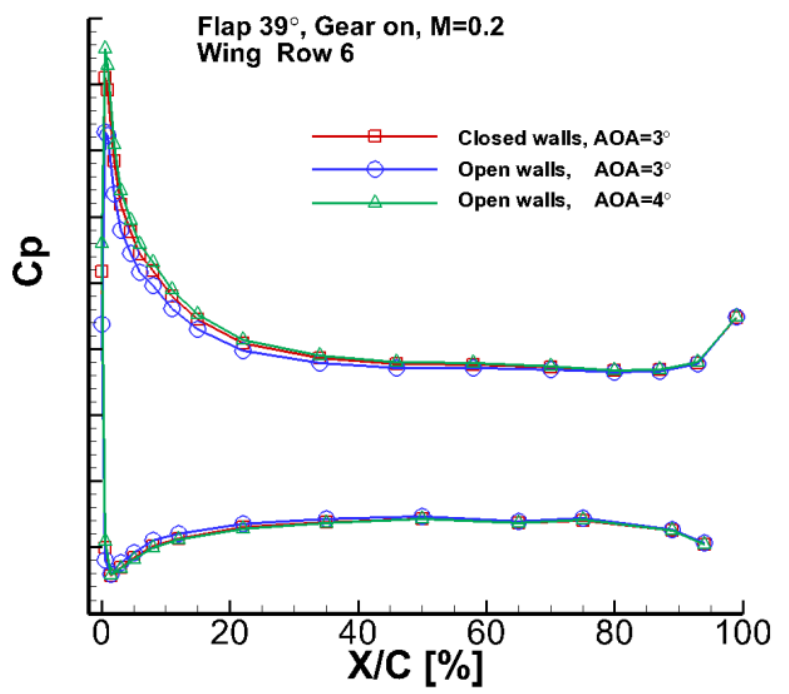

b) Wing row 6

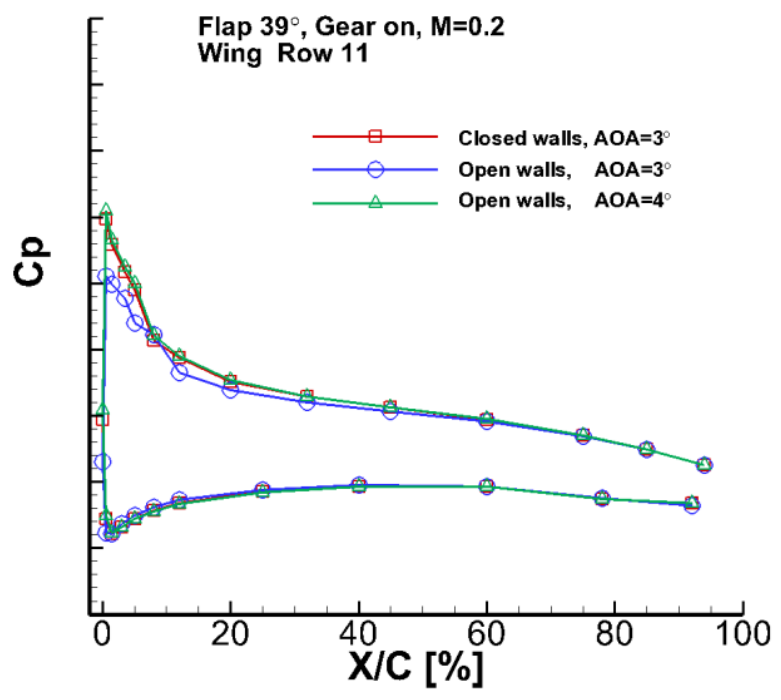

d) Wing row 11

Figure 22. Tunnel configuration effects on wing pressure distribution.

In contrast to the wing, the pressure field on the flap is expected to remain unaffected by the change in tunnel configuration. For angles of attack up to moderate values, the most critical parameter influencing the pressure field on the flap is its deflection angle relative to the wing. All other parameters are of secondary importance. This assertion is clearly demonstrated in Fig. 23, where sample pressures for flap rows adjacent to the edges and the mid-span are shown. Notice the independence of the flap pressure distribution from changes in tunnel configuration or wing angle of attack. The chordwise pressure distributions acquired with the tunnel walls closed and open are virtually indistinguishable. The same is true for the data obtained at two different angles of attack in the open-wall configura- 
tion. In fact, had we plotted the measured pressures at alpha $=2^{\circ}, 5^{\circ}$, or even $6^{\circ}$, no discernible differences would have emerged with what is shown in Fig. 23. For airframe noise measurement, the invariance of the flap pressure field to tunnel configuration or angle of attack changes is advantageous. During future wind tunnel measurements, matching the angle of attack of a landing Gulfstream aircraft becomes less of a concern as long as the flap deflection angle is set properly.

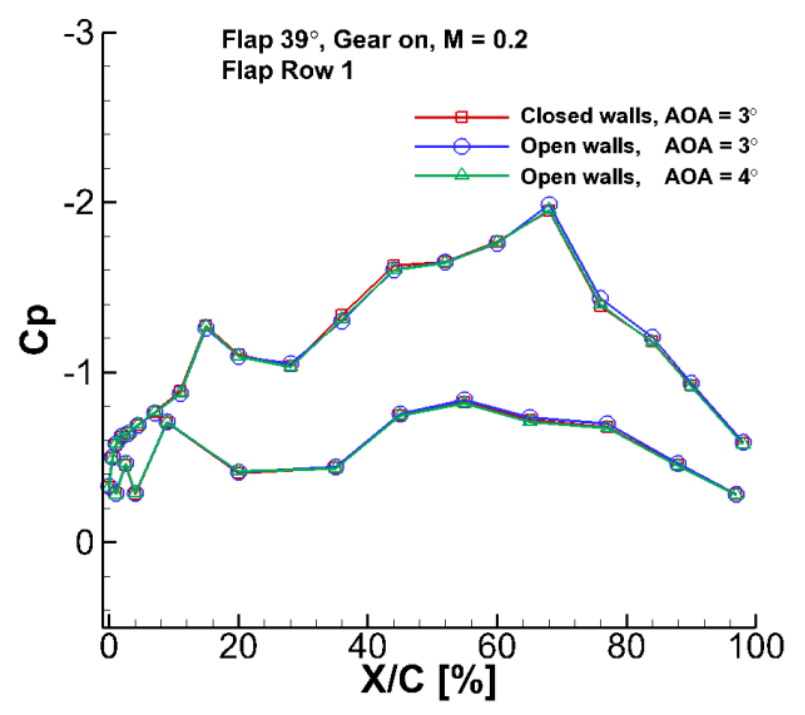

a) Flap inboard edge

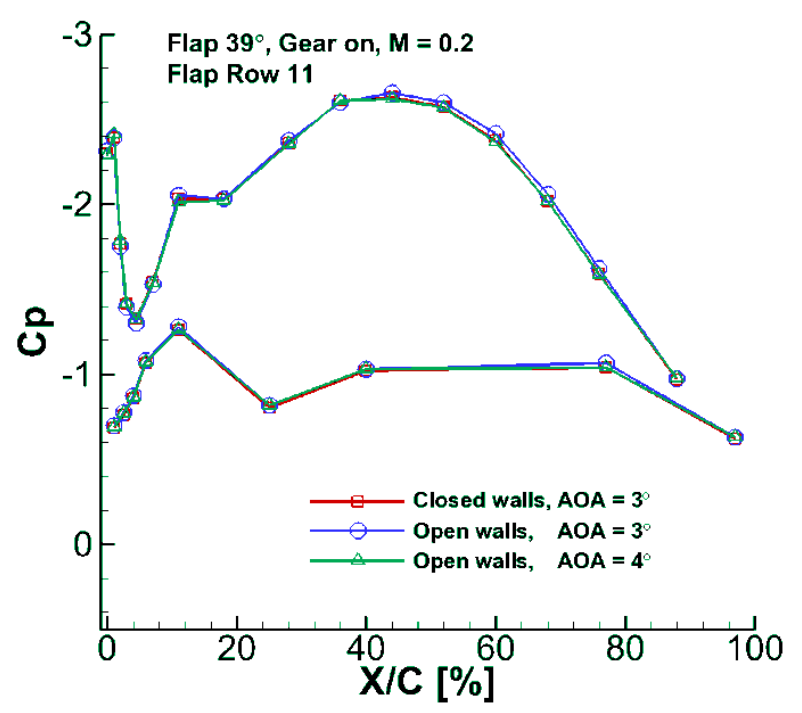

b) Flap outboard edge

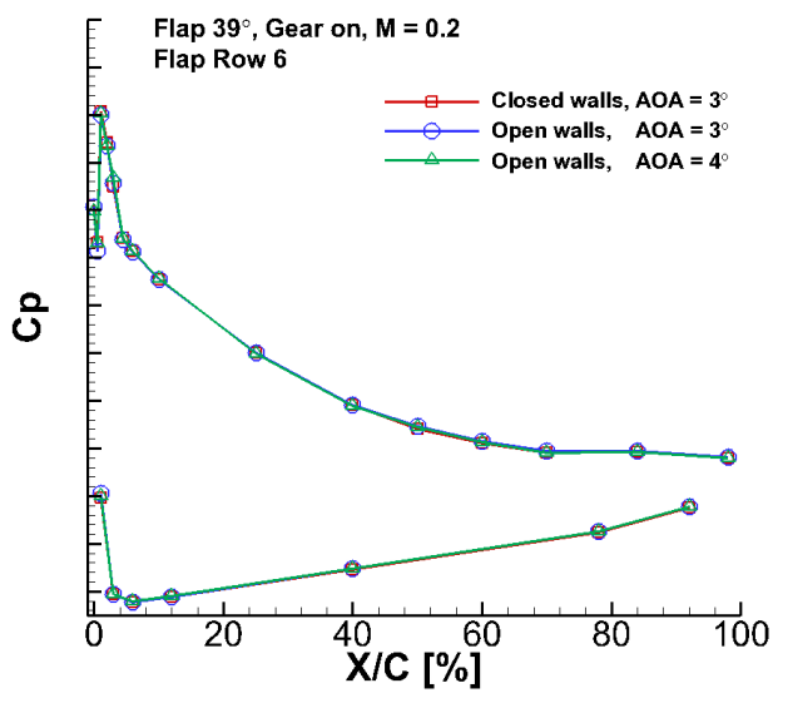

c) Flap mid-span

Figure 23. Tunnel configuration effects on flap pressure distribution.

\section{Concluding Remarks}

Under an ongoing NASA-Gulfstream partnership, an $18 \%$ scale semi-span model of a Gulfstream aircraft was designed and fabricated to conduct airframe noise research and develop effective noise reduction technologies. A high level of geometric fidelity was maintained for the model to allow direct comparison with the previously obtained full-scale acoustic data, and with results from upcoming flight tests. The model was instrumented with a significant number of surface mounted static ports and dynamic sensors to capture the global, as well as local, character of the steady and unsteady pressure field. 
The aeroacoustic testing of the $18 \%$ model is to be accomplished in two phases. The initial phase, reported here, was conducted in the LaRC $14 \times 22$ tunnel to fully map the aerodynamic characteristics of the model. Flap deflection angles of $39^{\circ}, 20^{\circ}$, and $0^{\circ}$ with the main landing gear on and off were tested at Mach numbers of $0.16,0.20$, and 0.24 . Only results for the $39^{\circ}$ flap deflection (landing condition) are presented in this paper. Additionally, for each configuration, the model was tested with the $14 \times 22$ tunnel both in the closed-wall and open-wall (jet) modes. The aerodynamic measurements acquired in this entry comprise the global forces (lift and drag) plus extensive steady and unsteady surface pressures. The latter are presented in a companion paper.

Analysis of the measured forces indicates that the lift, drag, and stall characteristics of the $18 \%$ model compare well with the corresponding Gulfstream aircraft high Reynolds number flight data. The favorable comparison between the wind-tunnel and full-scale data will allow the semi-span model to be used as a test bed for developing/evaluating airframe noise reduction concepts under a relevant environment. Comparison of the surface pressures obtained at the three Mach numbers revealed no significant Reynolds number effects. Considering that the model had gone through numerous configuration changes during the test, good data repeatability was displayed by the surface pressures. The pressure field at the flap inboard edge showed significant flow interaction with the wake emanating from the main landing gear. It was revealed that removing the gear significantly affects local pressures by allowing the formation of a stronger vortex at the edge, resulting in a broader and higher suction peak.

Comparison of the aerodynamic measurements obtained with the tunnel in the closed- and open-wall configurations showed that the model maintains its aerodynamic character over the entire angle-of-attack range, including the stall regime. This favorable comparison alleviates most of the concerns and trepidations associated with open-jet testing. As a result, the acoustic and off-surface flow measurements, planned for the second entry, will be conducted with the $14 \times 22$ tunnel in the open-wall mode. It is anticipated that the present aerodynamic data, together with the second phase off-surface velocity and far field acoustic measurements, augmented with full-scale data, will constitute a comprehensive and unique dataset to validate and improve our prediction tools for airframe noise.

\section{Acknowledgments}

This work was supported by the Environmentally Responsible Aviation (ERA) project under the Integrated System Research Program (ISRP) of NASA. As is the case with the development of any large scale model, the design, fabrication, and instrumentation of the present $18 \%$ Gulfstream aircraft model were the culmination of many years of hard work by a dedicated group of people (too numerous to be listed here) at NASA Langley Research Center. Some of the key personnel leading the model development task were William D. Castle, Scott Verden, Glenn Ormsby, Robert Harris, Gary Wainwright, and Sandy Webb. A special thank you goes to E. Thomas Hall for masterfully instrumenting the model far beyond what was deemed possible. We also would like to thank the staff of the Langley $14 \times 22$ facility for their outstanding support and execution of a highly productive test entry. We appreciate the support provided by Donald Day during model installation in the $14 \times 22$ tunnel. In addition, we would like to express our gratitude to Luther Jenkins and Meelan Choudhari for their valuable assistance in resolving the boundary layer transition issues and the placement of the boundary layer trips at the leading edge of the wing.

We would also like to acknowledge the valuable contributions of the Applied Aerodynamics and Acoustics Groups, and other Gulfstream personnel, for their many services enabling the design and testing of the $18 \%$ scale Semi-span model. In particular, .Michael Foster of the Applied Aerodyanamics Group for his assistance with comparative aircraft characteristics and Gerardo Ramirez of the Structural Design Team for assistance with the aircraft geometry essential for building the semi-span model.

\section{References}

${ }^{1}$ Michel, U., Barsikow, B., Helbig, J., Hellmig, M., and Schüttpelz, M., "Flyover Noise Measurements on Landing Aircraft with a Microphone Array," AIAA Paper 98-2336, May 1998.

${ }^{2}$ Piet, J.-F., Elias, G., and Lebigot, P., "Localization of Acoustic Sources from a Landing Aircraft with a Microphone Array," AIAA Paper 99-1811, May 1999.

${ }^{3}$ Pott-Pollenske, M., Dobrzynski, W., Buchholz, H., Gehlhar, B., and Walle, F., "Validation of a Semiempirical Airframe Noise Prediction Method through Dedicated A319 Flyover Noise Measurements," AIAA Paper 2002-2470, June 2002.

${ }^{4}$ Stoker, R., Guo, Y., Streett, C. L., and Burnside, N., "Airframe Noise Source Locations of a 777 Aircraft in Flight and Comparisons with Past Model Tests,” AIAA Paper 2003-3232, May 2003.

${ }^{5}$ Elkoby, R., Brusniak, L., Stoker, R., Khorrami, M. R., Abeysinghe, A., and Moe, J.W., "Airframe Noise Results from the QTD II Flight Test Program,” AIAA Paper 2007-3457, May 2007.

${ }^{6}$ Khorrami, M. R., Lockard, D. P., Humphreys, Jr., W. M., Choudhari, M. M., and Van de Ven, T., "Preliminary Analysis of Acoustic Measurements from the NASA-Gulfstream Airframe Noise Flight Test," AIAA Paper 2008-2814, May 2008. 
${ }^{7}$ Horne, W. C., James, K. D., Arledge, T. K., Soderman, P. T., Burnside, N., and Jaeger, S. M., "Measurements of 26\%-scale 777 Airframe Noise in the NASA Ames 40- by 80 Foot Wind Tunnel," AIAA Paper 2005-2810, May 2005.

${ }^{8}$ Jaeger, S. M., Burnside, N. J., Soderman, P. T., Horne, W. C., and James, K. D., "Microphone Array Assessment of an Isolated, 26\%-Scale, High Fidelity Landing Gear," AIAA Paper 2002-2410, June 2002.

${ }^{9}$ Neuhart, D. H., Khorrami, M. R., and Choudhari, M. M., “Aerodynamics of a Gulfstream G550 Nose Landing Gear Model,” AIAA Paper 2009-3152, May 2009.

${ }^{10}$ Zawodny, N. S., Liu, F., Yardibi, T., Cattafesta, Jr., L. N., Khorrami, M. R., Neuhart, D. H., and Van de Ven, T., “A Comparative Aeroacoustic Study of a 1/4-Scale Gulfstream G550 Aircraft Nose Landing Gear Model,” AIAA Paper 2009-3153, May 2009.

${ }^{11}$ Khorrami, M. R. and Neuhart, D. H, "Aeroacoustic Studies of a High-Fidelity Aircraft Model: Part 2- Unsteady Surface Pressures," Paper to be presented at the AIAA/CEAS Aeroacoustics Conference, June 2012.

${ }^{12}$ Iyer, V., "A Wall Correction Program Based on Classical Methods for the National Transonic Facility (Solid Wall or Slotted Wall) and the 14x22 -Ft Subsonic Tunnel at NASA LaRC," NASA CR-2004-213261, October 2004.

${ }^{13}$ Neuhart, D. H. and McGinley, C. B., "Free-Stream Turbulence Intensity in the Langley 14- by 22-Foot Subsonic Tunnel," NASA TP-2004-213247, 2004.

${ }^{14}$ Gentry, C. L., Jr., Quinto, P. F., Gatlin, G. M., and Applin, Z. T., "The Langley 14- by 22-Foot Subsonic Tunnel: Description, Flow Characteristics, and Guide for Users," NASA TP-3008, 1990.

${ }^{15}$ Rae, Jr., W.H. and Pope, A., Low-Speed Wind Tunnel Testing, 2nd ed., John Wiley \& Sons, New York, 1984, Chaps. 6. 